S0131 - AN IBM-650 CODE TO SOLVE PRESSURE AND THERMAL STRESS PROBLEMS IN CORE SUBASSEMBLY PLATES

AUGUST 1959

CONTRACT AT-11-1-GEN-14

BETTIS PLANT-PITTSBURGH, PA. OPERATED FOR THE U.S. ATOMIC ENERGY COMMISSION BY BETTIS ATOMIC POWER DIVISION, WESTINGHOUSE ELECTRIC CORPORATION

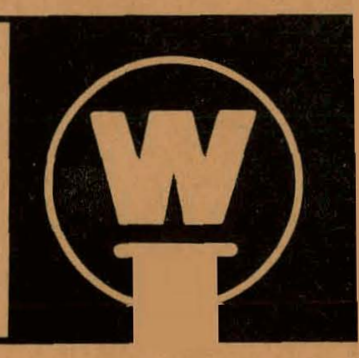




\section{DISCLAIMER}

This report was prepared as an account of work sponsored by an agency of the United States Government. Neither the United States Government nor any agency Thereof, nor any of their employees, makes any warranty, express or implied, or assumes any legal liability or responsibility for the accuracy, completeness, or usefulness of any information, apparatus, product, or process disclosed, or represents that its use would not infringe privately owned rights. Reference herein to any specific commercial product, process, or service by trade name, trademark, manufacturer, or otherwise does not necessarily constitute or imply its endorsement, recommendation, or favoring by the United States Government or any agency thereof. The views and opinions of authors expressed herein do not necessarily state or reflect those of the United States Government or any agency thereof. 


\section{DISCLAIMER}

Portions of this document may be illegible in electronic image products. Images are produced from the best available original document. 
UC-80: Reactors-General TID-4500 (14th Ed.)

\title{
S0131 - AN IBM-650 CODE TO SOLVE PRESSURE AND THERMAL STRESS PROBLEMS IN CORE SUBASSEMBLY PLATES
}

C. M. Friedrich

\section{Contract AT-11-1-GEN-14}

August 1959

Price $\$ 1.00$

Available from the Office of Technical Services,

Department of Commerce,

Washington 25, D. C. expression of the opinion of Westinghouse. When this memorandum is distributed externally, it is with the express understanding that Westinghouse makes no representation as to completeness, accuracy, or usability of information contained therein.

\author{
BETTIS PLANT • PITTSBURGH, PA. \\ OPERATED FOR THE U.S. ATOMIC ENERGY COMMISSION BY \\ BETTIS ATOMIC POWER DIVISION, WESTINGHOUSE ELECTRIC CORPORATION
}


Manager, Pittsburgh Naval Reactors Operations Office, AEC

Carnegie Institute of Technology, C. Zorowski

Westinghouse - East Pittsburgh, D. J. Smith, Patent Department

Westinghouse Research Laboratories, N. C. Small

This report was prepared as an account of Government sponsored work. Heither the United States, nor the Commission, nor any person acting on behalf of the Commission:

A. Makes any warranty or representation, expressed or implied, with respect to the accuracy, completeness, or usefulness of the information contained in this report, or that the use of any information, apparatus, method, or process disclosed in this report may not infringe privately owned rights; or

B. Assumes any liabilities with respect to the yse of. or for damages resilting from the use of any information, apparatus, method, or process disclosed in this report.

As used in the above, "person actina on behalf of the commissinn" includes any emplaye, or contractor of the commission, or employe of such contractor, to the extent that such omployo or oontraotor of the Cemmisoion. ar employe of suili curvtiacitur prepares, llissemi= nates, or provides access to, any information pursuant to his employment or contract with the Commission, or his employment with such contractor. 
Page No.

\author{
INTRODUCTION \\ SIMPLE PLATE THEORY \\ Cantilever Plate Notation \\ Plate Theory \\ PARALLEL PLATE \\ Notation \\ Deflection Equations

\section{MATRIX EQUATIONS} \\ Matrix Rules \\ Basic Formulae \\ Parallel Plate Formulae \\ Combination of Parallel Plates \\ INPUT AND OUTPUT DATA \\ Input Cards \\ Output Cards \\ REFERENCE
}

1

3

3

4

7

7

9

10

10

12

16

17

18

18

21

21 
In the design of nuclear reactor core subassemblies, a stress analysis is often made of a subassembly whose plates differ in geometry, in reactor coolant pressure loading, and in temperature distribution. Bettis code SOl3l was developed for the IBM-650 computer to assess the adequacy of the subassembly design and to assist in determining acceptable manufacturing tolerances. The output of the code gives redundant weld reactions, deformations, and stresses in the individual plates.

\title{
S0131-AN IBM-650 CODE TO SOLVE PRESSURE AND THERMAL STRESS PROBLEMS IN CORE SUBASSEMBLY PLATES
}

\author{
C. M. Friedrich
}

\section{INTRODUCTION}

The two main causes of cross section stresses and deflections in the plates of a rectangular subassembly in a nuclear reactor core are (1) thermal stresses produced by heat generation in the plates containing uranium and (2) pressure stresses which arise when the fluid pressures in the channels between plates and outside the subassembly have different values. Various IBM-650 codes, using the Wolontis symbolic program, have been developed at Bettis to calculate the stresses and deflections.

Code $50102 *$ is based on the "beam on an elastic foundation" theory and is suitable for dimensional parametric survey studies before detailed stress analysis is required:

Code W0040* is based on finite difference theory and is restricted to subassemblies with identical fuel plates, It gives the same results as code S0131 when applicable.

Code $59013 \dagger$ determines the moment distribution in a Vierendeel truss subjected to external loads and is therefore not suited to the problem of determining pressure and temperature stresses.

Code S0131 is particularly designed for a subassembly whose fuel plates differ in geometry as well as in pressure loading and temperature distribution. The differences can occur by design, by manufacturing tolerances, and by non-uniform thermal neutron flux distribution. The geometry is restricted to I-beam shaped clad fuel plates welded together to form two side plates as shown in Fig. 1. Dimensions, pressure loading, and temperature distribution are assumed to be symmetrical about the two centerlines and are assumed not to vary axially in the neighborhood of the cross sections

* "Stress Solution for Plate Type Seed Subassemblies," by F. V. Naugle, Bettis Plant

* "Subassembly Pressure and Temperature Stress," by N. S. Small and V. Davis, Bettis Plant

$\dagger$ "Moments in a Vierendeel Truss," by A. Martenson, Bettis Plant 


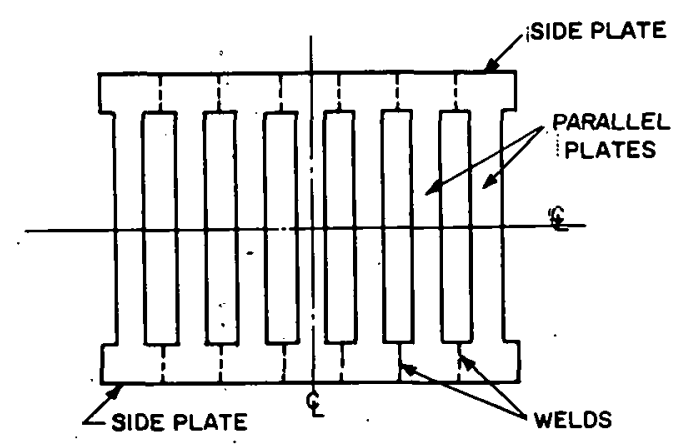

Fig. I Typical Cross Section of 1-Beam Shaped Clad Fuel under consideration. The plane cross sections are assumed to remain plane and parallel to each other with no net force on the cross sections in the axial direction.

The method of solution in code S0131 consists of the following steps:

1) Consider a portion of the subassembly between two plane cross sections a unit distant apart in the axial direction perpendicular to the cross section.

2) Cut the cross section at the side plate welds and consider the weld reactions to be external loads acting on the I-beam shaped plates on either side of each weld cut.

3) Because of symmetry, only half of each I-beam need be considered. Each half is a $\mathrm{T}$-beam as shown in Fig. 2. Consider the $T$-beam to be composed of three simple uniform flexible beams connected to a rigid element as shown in Fig. 3.

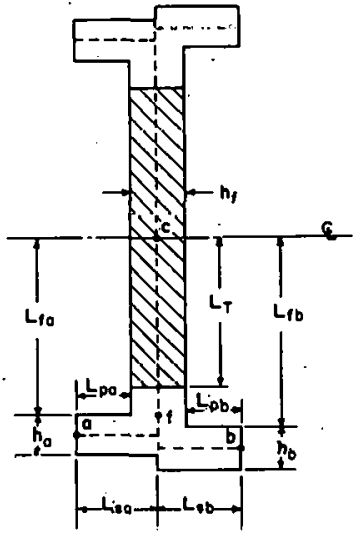

Fig. 2 Geometry of a Parallel Plate

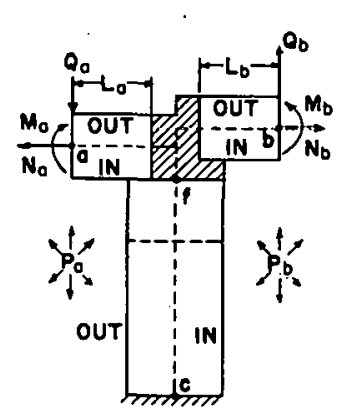

TOGETHER

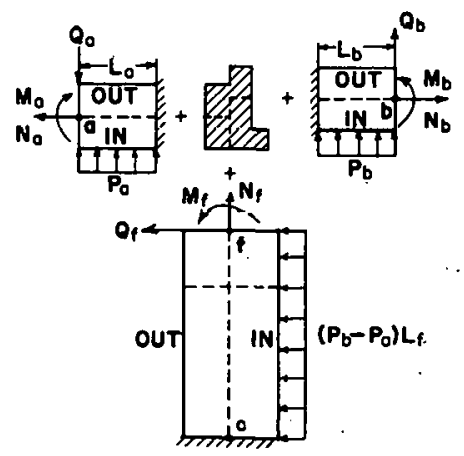

SEPARATE

Hig. 3 Free Body Elements of a Parallel Plate

4) The deflection equations and stress equations for each uniform beam, as developed in the following section, are used to determine the stresses and deflections of each uniform beam in terms of weld reactions, pressure loading, and temperature distribution.

5) The deflections for the three uniform beam elements of each $\mathrm{T}$-beam are combined to give the weld deflections of each $\mathrm{T}$-beam in terms of weld reactions, pressure loading, and temperature distribution, as described under the heading. "Parallel Plate."

6) The weld deflections of adjoining $T$-beams are equated to give relationships that determine the weld reactions in terms of pressure loading and temperature distribution, as described under the heading "Matrix Equations."

7) Once the weld reactions are known, the equations of step 4 can be used to give the stresses and deflections of all flexible elements in the subassembly cross section in terms of pressure loading and temperature distribution.

The input and output cards for code S0131 are described under the heading "Input and Output Data." 


\section{SIM PLE PLATE THEORY}

\section{Cantilever Plate Notation}

Each parallel plate can be separated into free bodies consisting of uniform plates with uniform pressure and temperature distributions. The deflections of each uniform plate are found relative to the tangent line at one end, which is the usual cantilever orientation shown in Fig. 4, along with the positive directions of all variables.

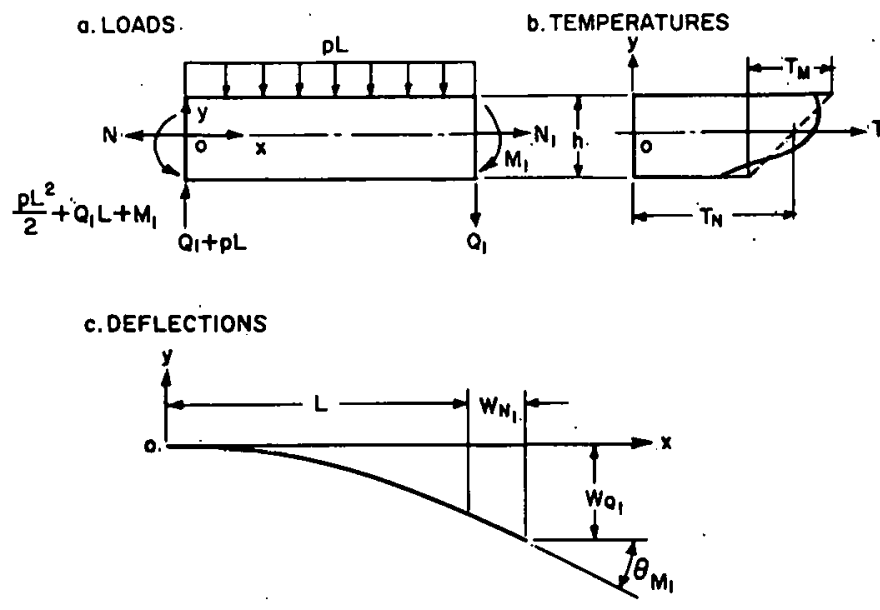

Fig 4. Iniform Cantilever

$\mathrm{M}_{1}=\mathrm{M}$ at $\mathrm{x}=\mathrm{L}$

Q = shear force per unit depth, Ib/in.

$Q_{1} \quad=Q$ at $x=L$

$\mathrm{N} \quad=$ tensile force per unit depth (negative if compressive), $\mathrm{lb} / \mathrm{in}$.

$\mathrm{N}_{1}=\mathrm{N}$ at $\mathrm{x}=\mathrm{L}$

$\mathrm{p} \quad=$ pressure on surface $\mathrm{y}=0.5 \mathrm{~h}$ minus pressure on surface $\mathrm{y}=-0.5 \mathrm{~h}, \mathrm{psi}$

${ }^{\theta} \mathbf{M}_{1}\left\{\begin{array}{l}=\text { working deflection of } M_{1} \\ =\text { angular deflection at right end, radians }\end{array}\right.$

$\mathbf{w}_{\mathbf{Q}_{1}}\left\{\begin{array}{l}\text { = working deflection of } \mathbf{Q}_{1} \\ =\text { deflection in the - y direction at right end, in. }\end{array}\right.$

$\mathrm{w}_{\mathrm{N}_{1}}\left\{\begin{array}{l}=\text { working deflection of } \mathrm{N}_{1} \\ =\text { elongation of the plate in the } \mathrm{x} \text { direction, } \cdot \mathrm{in} .\end{array}\right.$

$\mathrm{T} \quad=$ temperature in plate at distance $\mathrm{y}$ from the middle surface of the plate, measured above the side plate temperature, ${ }^{\circ} \mathrm{F}$ (each side plate is assumed to be at zero reference temperature)

$\mathrm{T}_{\mathrm{N}}\left\{\begin{array}{l}=\text { effective tensile temperature, }{ }^{\circ} \mathrm{F} \\ =\frac{1}{\mathrm{~h}} \int_{-0.5 \mathrm{~h}}^{+0.5 \mathrm{~h}} \mathrm{~T} \mathrm{dy}\end{array}\right.$

and

$$
\mathrm{T}_{\mathrm{M}}\left\{\begin{array}{l}
=\text { effective bending temperature, }{ }^{\circ} \mathrm{F} \\
=\left(\frac{12}{\mathrm{~h}^{2}}\right) \int_{-0.5 \mathrm{~h}}^{+0.5 \mathrm{~h}} \mathrm{~T} \mathrm{y} \mathrm{dy}
\end{array}\right.
$$

Let

$\mathbf{x}=$ distance along centerline of cantilever beam from left end, in.

$=$ distance in cross section from centerline, in.

= axial distance to cross section from bottom of subassembly, in.

$=$ thickness of plate in y direction, in.

$\mathrm{L} \quad=$ length of plate in $\mathrm{x}$ direction, in. = bending moment per unit depth (unit depth is in $z$ direction), $1 b$ 


\section{Bending Theory Stress}

The basic elasticity equations (Ref 1) for the cantilever plate.are

$$
\begin{aligned}
& E \epsilon_{x}=S_{x}-\nu S_{z}+E \alpha T \\
& E \epsilon_{z}=S_{z}-\nu S_{x}+E \alpha T
\end{aligned}
$$

and the basic assumptions are

$$
\begin{gathered}
\epsilon_{x}=A+B y, \\
S_{y}=0 \\
\epsilon_{z}=\alpha T_{z}
\end{gathered}
$$

where

$\mathbf{E}=$ tensile modulus of elasticity, psi,

$\epsilon_{1}=$ strain in direction 1, 1n. / in. ,

$\mathrm{S}_{\mathrm{i}}=$ stress in direction $\mathrm{i}, \mathrm{psi}$,

$\nu=$ Poisson'e ratio,

$\alpha^{\prime}=$ theirmal expansion coefficient, in. /in. $-^{\circ} \mathrm{F}$,

$\dot{A}=$ average strain coefficient, in. /in. ,

$\mathrm{B}$ = bending strain coefficient, in. $/$ in. ${ }^{2}$, and

$\mathrm{T}_{\mathrm{z}}$ = average temperature of subassembly cross section, measured above side plate temperature, ${ }^{\circ} \mathrm{F}$.

'The assumptions of Eq (2) state, in effect, that

1) the plate cross section remains a plane during bending,

2) the stress $S_{y}$ in the $y$ direction is negligible in comparison with $S_{x}$ and $S_{z}$, and

3) subassembly cross sections remain parallel.

Eliminating $\epsilon_{\mathrm{z}}$ between $\mathrm{Eq}(1 \mathrm{~B})$ and $\mathrm{Eq}(2 \mathrm{C})$ gives

$$
S_{z}=\nu S_{x}+E \alpha\left(T_{z}-T\right)
$$

which is used to determine axial stresses in code S0131. The cross section stress is determined from equilibrium relations between $M$ and $N$ obtained from Éqs (1A), (2A), (3). First, elimination of $\epsilon_{x}$ and $S_{z}$ in Eqs (1A), (2A), and (3) gives

$$
s_{\dot{x}}=\left(\frac{E}{l-v^{2}}\right)\left[A+B y+v \alpha T_{z}-(l+v) \alpha T\right] \text {. }
$$

Next, consideration of equilibrium on the plate cross section at a general position $x$ gives

$$
\begin{gathered}
N=\int_{-0.5 h}^{+0.5 h} s_{x} d y \\
M=\int_{-0.5 h}^{+0.5 h} S_{x} y d y .
\end{gathered}
$$

Substituting Eq (4) into Eq (5) and solving for the strain coefficients A and B give 


$$
\begin{aligned}
& \mathrm{A}=\left(\frac{1-v^{2}}{\mathrm{Eh}}\right) \mathrm{N}+(1+v) \alpha \mathrm{T}_{\mathrm{N}}-v \alpha \mathrm{T}_{\mathrm{z}} \\
& \mathrm{B}=\left(\frac{12}{\mathrm{~h}^{3}} \cdot \frac{1-v^{2}}{\mathrm{E}}\right) \mathrm{M}+\left(\frac{1+\nu}{\mathrm{h}}\right) \alpha \mathrm{T}_{\mathrm{M}}
\end{aligned}
$$

Finally, elimination of $A$ and $B$ from Eqs (4) and (6) gives

$$
S_{x}=\left(\frac{1}{h}\right) N+\left(\frac{12 y}{h^{3}}\right) M+\left(\frac{E \alpha}{1-v}\right)\left[T_{N}+\frac{y}{h} T_{M}-T\right] \text {. }
$$

which is a useful equation for cross section stresses. It is to be noted that if the temperature distribution is linear, then

$$
T=T_{N}+(y / h) T_{M}
$$

and

$$
S_{x}=(1 / h) N+\left(12 y / h^{3}\right) M
$$

Bendirig Theory Deflections

Physically, the coefficient A in Eq (2) is the elongation of the plate per unit length $x$, and the coefficient $B$ is rate of change of slope per unit length $x$; that is,

$$
\frac{d w_{N}}{d \mathbf{x}}=A
$$

and

$$
\frac{\mathrm{d} \theta_{\mathbf{M}}}{\mathrm{dx}}=\mathbf{B}
$$

Substitution of A and B from Eq (6) gives

$$
\begin{aligned}
& \frac{{ }^{d w_{N}}}{d x}=\left(-\frac{1-v^{2}}{E h}\right) N+(1+v) \alpha T_{N}-v \alpha T_{Z} \\
& \frac{d{ }^{\theta}}{d x}=\left(\frac{12}{h^{3}} \cdot \frac{1-v^{2}}{E}\right) M+\left(\frac{1+v}{h}\right) \alpha T_{M}
\end{aligned}
$$

Before these equations can be integrated with respect to $x$, the loads must be given as functions of $x$. By inspection of Fig. $4 a$, it is seen that

$$
\begin{gathered}
N=N_{1} \\
Q=Q_{1}+p(L \div x) \\
M=M_{1}+Q_{1}(L-x)+0.5 p(L-x)^{2} .
\end{gathered}
$$

Substituting these values into $\mathrm{Eq}(8)$ and integrating over the general range 0 to $\mathrm{x}$ gives the elongation and slope as

$$
\begin{gathered}
\mathrm{w}_{\mathrm{N}}=\left[\left(\frac{1-\nu^{2}}{\mathrm{Eh}}\right) \mathrm{N}_{1}+(1+v) \alpha \mathrm{T}_{\mathrm{N}}-v \alpha \mathrm{T}_{\mathrm{z}}\right] \mathrm{x} \\
\theta_{\mathrm{M}^{\prime}}=\left(\frac{12}{\mathrm{~h}^{3}} \cdot \frac{1-v^{2}}{\mathrm{E}}\right)\left[\mathrm{M}_{1} \mathrm{x}+\mathrm{Q}_{1}\left(\mathrm{Lx}-\frac{\mathrm{x}^{2}}{2}\right)+\mathrm{p}\left(\frac{\mathrm{L}^{2} \mathrm{x}}{2}-\frac{\mathrm{Lx}}{2}+\frac{\mathrm{x}^{3}}{6}\right)\right]+\left[\left(\frac{1+v}{\mathrm{~h}}\right) \alpha \mathrm{T}_{\mathrm{M}}\right] \mathrm{x}
\end{gathered}
$$


Thus, at $\mathbf{x}=\mathbf{L}$

$$
\begin{gathered}
\mathrm{w}_{\mathrm{N}_{1}}=\left(\frac{1-v^{2}}{\mathrm{E}} \cdot \frac{\mathrm{L}}{\mathrm{h}}\right) \mathrm{N}_{1}+\alpha \mathrm{L}\left[(1+v) \mathrm{T}_{\mathrm{N}}-v \mathrm{~T}_{\mathrm{z}}\right] \\
{ }_{\mathrm{M}_{1}}=\left(\frac{12}{\mathrm{~h}^{3}} \cdot \frac{1-v^{2}}{\mathrm{E}}\right)\left[\text { (L) } \mathrm{M}_{1}+\left(\frac{\mathrm{L}^{2}}{2}\right) \mathrm{Q}_{1}+\left(\frac{\mathrm{L}^{3}}{6}\right) \mathrm{p}\right]+\alpha\left(\frac{\mathrm{L}}{\mathrm{h}}\right)(1+v) \mathrm{T}_{\mathrm{M}} \cdot
\end{gathered}
$$

Since slope is the rate of change of deflection,

$$
\mathrm{dw}_{\mathrm{Q}} / \mathrm{dx}=\theta_{\mathrm{M}}
$$

Substitution of $\theta_{M}$ from Eq (10) and integration from 0 to $\mathrm{L}$ gives the end deflection as

$$
\mathrm{w}_{\mathrm{Q}_{1}}=\left(\frac{12}{\mathrm{~h}^{3}} \cdot \frac{1-v^{2}}{\mathrm{E}}\right)\left[\left(\frac{\mathrm{L}^{2}}{2}\right) \mathrm{M}_{1}+\left(\frac{\mathrm{L}^{3}}{3}\right) \mathrm{Q}_{1}+\left(\frac{\mathrm{L}^{4}}{8}\right) \mathrm{p}\right]+\alpha\left(\frac{\mathrm{L}^{2}}{2 \mathrm{~h}}\right)(1+v) \mathrm{T}_{\mathrm{M}} \text {. }
$$

\section{Shear Theory Stress}

Consider a unit depth of the cantilever plate in Fig. 5 bounded by the surfaces $x, x+d x, y$, and $y=0.5 h$. Let $S_{s}$ be the shear stress on the surface at $y$, positive as shown. Summing forces on the element in the $x$ direction gives

$$
\begin{gathered}
0=-\int_{y}^{0.5 h} s_{x} d y+s_{s} d x+\int_{y}^{0.5 h}\left(s_{x}+\frac{\partial s_{x}}{\partial x} d x\right) d y \\
s_{s}=-\int_{y}^{0.5 h}\left(\frac{\partial s_{x}}{\partial x}\right) d y .
\end{gathered}
$$

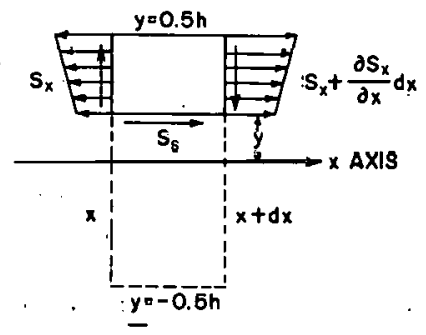

Fig. 5 Shear Stress

average stress $Q / h$.

In Eq (7) for $S_{x}$, the only quantity varying with $x$ is M. From Fin ( $9 C$ ), $\partial M / \partial x=-Q_{1}-p(L-x)$ which, asconrding to Fiq (9B), is

$$
\frac{\partial M}{\partial x}=-Q \text {. }
$$

Substituting $3_{x}$ frün Ey (7) and $8 \mathrm{M} / \partial \mathrm{x}$ from Eq (14) into Eq (13) and iitegialing give

$$
S_{S}=\left(\frac{1.5}{h}\right)\left(1-\frac{4 y^{2}}{h^{2}}\right) Q \text {. }
$$

The maximum shear stress at $y=0$ is seen to be $50 \%$ more than the

\section{Shear Theory Deflection}

The shear strain energy in the plate per unit cross section area is

$$
\mathrm{dU}_{\mathrm{S}}=\frac{\mathrm{S}_{\mathrm{S}}}{2}\left(\frac{2(1+v)}{E}\right) \mathrm{dxdy}
$$

so that the total shear strain energy is, by use of Eq (9) and Eq (15),

$$
U_{S}=\frac{1+v}{E} \int_{0}^{L} d x \int_{-0.5 h}^{+0.5 h} d y\left[\left(\frac{1.5}{h}\right)\left(1-\frac{4 y^{2}}{h^{2}}\right)\left(Q_{1}+p L_{1}-p x\right)\right]^{2} .
$$

By Castigliano's theorem, the working deflection of load $Q_{1}$ produced by the shear strain energy $U_{S}$ is 


$$
\left(w_{Q_{1}}\right)_{s}=\frac{\partial U_{s}}{\partial Q_{1}} .
$$

Substituting $\mathrm{U}_{\mathrm{S}}$ into this equation and simplifying gives

$$
\left(\mathrm{w}_{\mathrm{Q}_{1}}\right)_{\mathrm{s}}=\left[\frac{2.4(1+\nu)}{\mathrm{Eh}}\right]\left[(\mathrm{L}) \mathrm{Q}_{1}+\left(\frac{\mathrm{L}^{2}}{2}\right) \mathrm{p}\right]
$$

Thus, the total working deflection of $Q_{1}$ is

$$
{ }^{w_{Q_{1}}}=\left[{ }^{w_{Q_{1}}} \text { from Eq (12) }\right]+\left(w_{Q_{1}}\right)_{s}
$$

or

$$
\begin{aligned}
& w_{Q_{1}}=\left(\frac{6 L^{2}}{h^{3}} \cdot \frac{1-\nu^{2}}{E}\right) M_{1}+\left(\frac{4 L^{3}}{h^{3}} \cdot \frac{1-v^{2}}{E}+\frac{2 \cdot 4 L}{h} \cdot \frac{1+v}{E}\right) Q_{1} \\
& +\left(\frac{1.5 L^{4}}{h^{3}} \cdot \frac{1-\nu^{2}}{E}+\frac{1.2 L^{2}}{h} \cdot \frac{1+\nu}{E}\right) p+\alpha\left(\frac{L^{2}}{2 h}\right)(1+v) T_{M} .
\end{aligned}
$$

PARALLEL PLATE

Notation

Geometry

Each of the parallel plates can be considered to be composed of uniform plates with uniform pressure and temperature loadings. The loads on the uniform plates, determined from the loads on the parallel plate, give the deflections of the uniform plates. These deflections can be combined to give the total weld deflections of the parallel plate. A systematic notation, however, is needed first. As shown in Fig. 2, let

a = subscript for the middle surface of the side plate at the left weld

$\mathrm{b} \quad=$ subscript for the middle surface of the side plate at the right weld

$c \quad=$ subscript for the middle surface of the parallel plate itse if at the center

$h_{a}=$ thickness of left side plate, in.

$h_{b}=$ thickness of right side plate, in.

$h_{f}=$ thickness of parallel plate, in.

$\mathrm{L}_{\mathrm{T}}=$ half of the heated length of the parallel plate, in. .

$L_{f a}=$ half of the length of the channel at weld $a$, in.

$L_{f b}=$ half of the length of the channel at weid $b$, in.

$\mathrm{L}_{\mathrm{f}}=$ the smaller of $\mathrm{L}_{\mathrm{fa}}$ and $\mathrm{L}_{\mathrm{fb}}$, in. (In Fig. $2, \mathrm{~L}_{\mathrm{f}}=\mathrm{L}_{\mathrm{fa}}$ )

$L_{p a}=$ "overhang" length of side plate at weld $a$, in.

$\mathrm{L}_{\mathrm{pb}}=$ "ovcrhang" length of side plate at weld b, in.

$L_{s a}=L_{p a}+0.5 h_{f}=$ distance of weld a from the middle surface of the parallel plate, in.

$L_{s b}=L_{p b}+0.5 h_{f}=$ distance of weld b from the middle surface of the parallel plate, in. and

$f \quad=$ subscript for the middle surface of the side plate that is a distance $L_{f}$ from the centerline 


\section{Forces}

Free bodies of the flexible elements of the parallel plate are shown in Fig. 3, for which the notation is

$i=a, b$, or $f$

$N_{i}=$ tensile force per unit depth.at $i, 1 b /$ in.

$Q_{i}=$ shear force per unit depth at $i, l b / i n$.

$\mathbf{M}_{\mathbf{i}}$ = bending moment per unit depth at $i, \mathrm{lb}$

$\mathrm{L}_{\mathrm{a}}=$ effective flexible length of the side plate near weld $\mathrm{a}$, in.

$L_{b}=$ effective flexible length of the side plate near weld $b$, in.

$\mathbf{P}_{\mathbf{a}}=$ pressure in the channel at weld $a$, psi

and

$P_{b}=$ pressure in the channel at weld $b$, psi

By symmetry there is no shear at $c$, so that summing forces horizontally and solving for $\mathrm{N}_{b}$ gives

$$
\dot{\mathrm{N}}_{\mathrm{b}}=\mathrm{N}_{\mathrm{a}}-\mathrm{P}_{\mathrm{a}} \mathrm{L}_{\mathrm{fa}}+\mathrm{P}_{\mathrm{b}} \mathrm{L}_{\mathrm{fb}}
$$

By inspection of Fig. 3, the reactions at $f$ are seen to be

$$
\begin{aligned}
& N_{f}-Q_{a}+Q_{b}+P_{a} L_{p a}+P_{b} L_{p b} \\
& \left.Q_{f}={ }^{\prime} P_{a}-P_{b}\right) L_{f} \\
& M_{f}=+\left(L_{f a}+0.5 h_{a}-\dot{L}_{f}\right) N_{a}+\left(L_{s a}\right) Q_{a}-M_{a} \\
& \quad-\left(L_{f b}+0.5 h_{b}-L_{f}\right) N_{b}+\left(L_{s b}\right) Q_{b}+M_{b} \\
& =\left(L_{s a}=0.5 I_{p a}\right)\left(P_{a} T_{p a}\right)-0.5\left(I_{f}-I_{f a}\right)^{2} P_{a} \\
& \quad+\left(L_{s b}-0.5 L_{p b}\right)\left(P_{b}-L_{p b}\right)+0.5\left(L_{f}-L_{f b}\right)^{2} P_{b}
\end{aligned}
$$

It is to be noted that the channel pressurès are measured relative to the pressure on the outside surfaces of the two side plates. Ihe outside pressure is taken to be at zero reference pressure.

The flexible lengths $L_{a}$ and $L_{b}$ can be estimated by an empirical formula. * If $h_{a}$ is less than $h_{f}$, $L_{2}$ should be near $L_{p 2}$, and if $h_{2}$ is greater than $h_{f}, L_{a}$ should be near $L_{s a}$; therefore, let

$$
L_{a}=\left(h_{a} L_{s a}+h_{f} L_{p a}\right) /\left(h_{a}+h_{f}\right)
$$

arto

$$
L_{b}=\left(h_{b} L_{s b}+h_{f} L_{p b}\right) /\left(h_{b}+h_{f}\right)
$$

\section{Deflections}

Positive values of the following deflections are shown in Fig. 6:

$\theta_{a}=$ working deflection of $M_{a}=$ slope at weld $a$, radians

$w_{a}=$ working deflection of $Q_{a}=$ inward deflection at weld $a$, in.

* A study of photoelastic results would be better. 


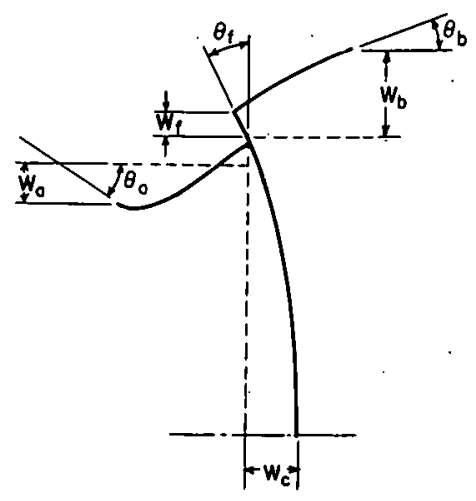

Fig. 6 Deflections of a Parallel Plate

$$
\begin{aligned}
\theta_{b} & =\text { working deflection of } M_{b}=\text { slope at weld } b \text {, radians } \\
w_{b} & =\text { working deflection of } Q_{b}=\text { outward deflection at weld } b, \\
& \text { in. }
\end{aligned}
$$

$\theta_{f}=$ slope of parallel plate at $f$, radians

$w_{f}=$ outward deflection of side plate at $f$, in.

and

$w_{c}=$ lateral bow of parallel plate towards the right at $c$, in.

\section{Deflection Equations}

The only part of the parallel plate that has a nonzero temperature distribution is the heated length $2 \mathrm{~L}_{\mathrm{T}^{*}}$. If the effective tensile temperature $\mathrm{T}_{\mathrm{N}}$ and effective bending temperature $\mathrm{T}_{\mathrm{M}}$ are assumed constant over the length $2 \mathrm{~L}_{\mathrm{T}}$, then the deflections at $\mathrm{f}$ and $\mathrm{c}$ are,

from Eq (11) and Eq (16),

$$
w_{f}=\left(\frac{1-v_{f}^{2}}{E_{f}} \cdot \frac{L_{f}}{h_{f}}\right) N_{f}+\alpha_{f} L_{T}\left(1+v_{f}\right) T_{N}
$$

where

$\mathrm{T}_{\mathrm{z}}$ is not used, since $\alpha_{\mathrm{f}}\left(1+. v_{\mathrm{f}}\right) \mathrm{T}_{\mathrm{z}}$ is the same for all plates and so has no effect on weld reactions,

$$
\begin{aligned}
\theta_{f}= & \left(\frac{1-v_{f}^{2}}{E_{f}} \cdot \frac{12 L_{f}}{h_{f}{ }^{3}}\right) M_{f}+\left(\frac{1-v_{f}^{2}}{E_{f}} \cdot \frac{6 L_{f}^{2}}{h_{f}{ }^{3}}\right) Q_{f} \\
& \left.+\left(\frac{1-v_{f}^{2}}{E_{f}} \cdot \frac{2 L_{f}^{3}}{h_{f}^{3}}\right)\left(P_{b}-P_{a}\right)+\alpha_{f}\left(\frac{L_{T}}{h_{f}}\right)\left(1+v_{f}\right) T_{M}\right],
\end{aligned}
$$

and

$$
\begin{aligned}
w_{c}= & \left(\frac{1-v_{f}^{2}}{E_{f}} \cdot \frac{6 L_{f}^{2}}{h_{f}^{3}}\right) M_{f}+\left(\frac{1-v_{f}^{2}}{E_{f}} \cdot \frac{4 L_{f}^{3}}{h_{f}^{3}}+\frac{1+v_{f}}{E_{f}} \cdot \frac{2 \cdot 4 L_{f}}{h_{f}}\right) Q_{f} \\
+ & \left.\left(\frac{1-v_{f}^{2}}{E_{f}} \cdot \frac{1 \cdot 5 L_{f}^{4}}{h_{f}^{3}}+\frac{1+v_{f}}{E_{f}} \cdot \frac{1.2 L_{f}^{2}}{h_{f}}\right)\left(F_{b}-P_{a}\right)+\alpha_{f}\left(\frac{L_{T}}{2 h_{f}}\right)\left(1+v_{f}\right) T_{M}\right] \\
& +\left[\alpha_{f}\left(\frac{L_{T}}{h_{f}}\right)\left(1+v_{f}\right) T_{M}\right]\left(L_{f}-L_{T}\right) .
\end{aligned}
$$

The last term in the $w_{c}$ equation is the lateral deflection at $\mathrm{f}$ caused by the thermal slope $\alpha\left(\mathrm{L}_{\mathrm{T}} / \mathrm{h}_{\mathrm{f}}\right)$ $(1+v)^{\prime} I_{M}$ acting over the length $\left(L_{f}-L_{T}\right)$.

The deflections at a are produced by the movement of the side plate caused by the deflections at $f$ and by the deformation of the side plate over the flexible length $L_{a}$; that is, if $P_{a}$ is assumed to act over the flexible length $\mathrm{L}_{a}$.

$$
\theta_{a}=-\theta_{f}+\left[\left(\frac{1-v_{a}^{2}}{E_{a}} \cdot \frac{12 L_{a}}{h_{a}^{3}}\right) M_{a}-\left(\frac{1-v_{a}^{2}}{E_{a}} \cdot \frac{6 L_{a}^{2}}{h_{a}^{3}}\right) Q_{a}+\left(\frac{1-v_{a}^{2}}{E_{a}} \cdot \frac{2 L_{a}^{3}}{h_{a}^{3}}\right) P_{a}\right]
$$




$$
\begin{aligned}
w_{a}= & -w_{f}+\left(L_{s a}\right) \theta_{f}+\left[-\left(\frac{1-v_{a}^{2}}{E_{a}} \cdot \frac{6 L_{a}^{2}}{h_{a}^{3}}\right) M_{a}\right. \\
+ & \left(\frac{1-v_{a}^{2}}{E_{a}} \cdot \frac{4 L_{a}^{3}}{h_{a}^{3}}+\frac{1+v_{a}}{E_{a}} \cdot \frac{2.4 L_{a}}{h_{a}}\right) Q_{a} \\
& \left.-\left(\frac{1-v_{a}^{2}}{E_{a}} \cdot \frac{1.5 L_{a}^{4}}{h_{a}^{3}}+\frac{1+v_{a}}{E_{a}} \cdot \frac{1.2 L_{a}^{2}}{h_{a}}\right) P_{a}\right]
\end{aligned}
$$

Similarly at $b$,

$$
\begin{aligned}
& \theta_{b}=\theta_{f}+\left[\left(\frac{1-v_{b}^{2}}{E_{b}} \cdot \frac{12 L_{b}}{h_{b}^{3}}\right) M_{b}+\left(\frac{1-v_{b}^{2}}{E_{b}} \cdot \frac{6 L_{b}^{2}}{h_{b}^{3}}\right) Q_{b}+\left(\frac{1-v_{b}^{2}}{E_{b}} \cdot \frac{2 L_{b}^{3}}{h_{b}^{3}}\right) P_{b}\right] \\
& w_{b}=w_{f}+\left(L_{s b}\right) \theta_{f}+\left[\left(\frac{1-v_{b}^{2}}{E_{b}} \cdot \frac{G L_{b}^{2}}{h_{b}^{3}}\right) M_{b}\right. \\
& +\left(\frac{1-v_{b}^{2}}{E_{b}} \cdot \frac{4 L_{b}^{3}}{h_{b}^{3}}+\frac{1+v_{b}}{E_{b}} \frac{2.4 L_{b}}{h_{b}}\right) Q_{b} \\
& \left.+\left(\frac{1-v_{b}^{2}}{E_{b}} \cdot \frac{1 \cdot 5 L_{b}^{4}}{h_{b}^{3}}+\frac{1+v_{b}}{E_{b}^{E}} \cdot \frac{1.2 L_{b}^{2}}{h_{b}}\right) P_{b}\right]
\end{aligned}
$$

\section{MATRIX EQUATIONS}

Matrix Rules

To keep track of the many simultaneous equations, the equations will be rewritten in matrix form in blocks of $2 \times 2$. The following rules will be used:

Matrix

A matrix is a block of 4 numbers arranged in two rows and two columns. For example, let

$$
A=\begin{array}{|l|l|}
\hline A_{11} & A_{12} \\
\hline A_{21} & A_{22} \\
\hline
\end{array}
$$

where $A_{i j}$ is the number in row $i$ and column $j$.

\section{Factor}

A number $k$ times a matrix $A$ is given by

$$
\begin{aligned}
& k A=k \times \begin{array}{|l|l|}
\hline A_{11} & A_{12} \\
\hline A_{21} & A_{22} \\
\hline
\end{array} \\
& \text { If } k=-1, \text { then }-A=
\end{aligned}
$$

\begin{tabular}{|l|l|}
\hline$-A_{11}$ & $-A_{12}$ \\
\hline$-A_{21}$ & $-A_{22}$ \\
\hline
\end{tabular}


Addition

A matrix A plus a matrix $B$ is given by

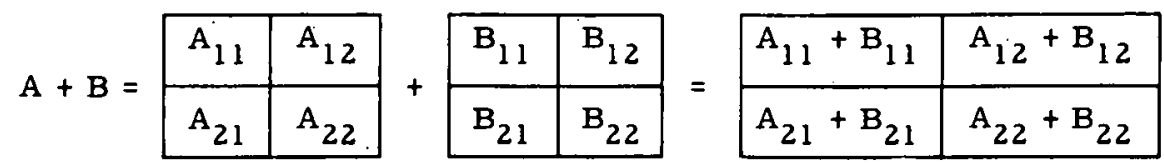

Subtraction

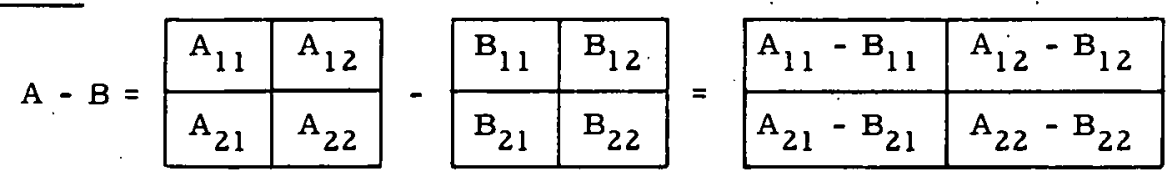

Multiplication

$$
A \times B=\begin{array}{|l|l|}
\hline A_{11} & A_{12} \\
\hline A_{21} & A_{22} \\
\hline
\end{array} \times \begin{array}{|l|l|}
\hline B_{11} & B_{12} \\
\hline B_{21} & B_{22} \\
\hline A_{21} B_{11}+A_{22} B_{21} & A_{21} B_{12}+A_{22} B_{22} \\
\hline
\end{array}
$$

In general, $A \times B \neq B \times A$. Note $A \times B \times C=(A \times B) \times C=A \times(B \times C)$.

\section{Zero}

A zero matrix has each element equal to 0.

$$
0=\begin{array}{|l|l|}
\hline 0 & 0 \\
\hline 0 & 0 \\
\hline
\end{array}
$$

$\underline{\text { Equality }}$

$A=B$ if and only if $A_{11}=B_{11}, A_{12}=B_{12}, A_{21}=B_{21}$, and $A_{22}=B_{22}$.

Unity

The unit matrix $U$ is defined by

$$
\mathrm{U}=\begin{array}{|l|l|}
\hline 1 & 0 \\
\hline 0 & 1 \\
\hline
\end{array}
$$

Note that $\mathrm{U} \times \mathrm{A}=\mathrm{A} \times \mathrm{U}=\mathrm{A}$ for any $\mathrm{A}$.

Transpose

The transpose $A^{\mathrm{T}}$ of matrix $\mathrm{A}$ is

$$
A^{T}=\begin{array}{|l|l|}
\hline A_{11} & A_{21} \\
\hline A_{12} & A_{22} \\
\hline
\end{array} \text {; that is, } A_{i j}^{T}=A_{j i} .
$$

Inverse

The inverse $A$ of matrix $A$ is

$$
A^{I}=\begin{array}{|c|c|}
\hline\left(\frac{A_{22}}{A_{11} A_{22}-A_{12} A_{21}}\right) & \left(\frac{-A_{12}}{A_{11} A_{22}-A_{12} A_{21}}\right) \\
\hline\left(\frac{-A_{21}}{A_{11} A_{22}-A_{12} A_{21}}\right) & \left(\frac{A_{11}}{A_{11} A_{22}-A_{12} A_{21}}\right) \\
\hline
\end{array}
$$


and it exists only if $A_{11} A_{22} \neq A_{12} A_{21}$. Note that $A^{I} \times A=A \times A^{I}=U$.

Basic Formulae

Side Plate Deflections at $\mathrm{f}$

Each force and deflection is separated into a term produced by pressure loading (p) and a term produced by thermal loading ( $t$ ). From Eq (19), *
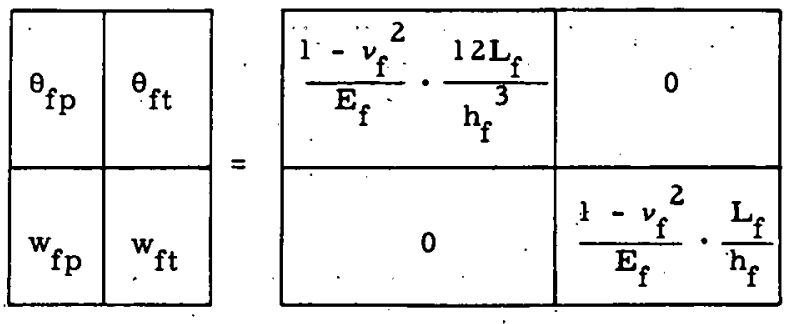

$$
\begin{array}{|c|c|}
\hline\left(\frac{1-v_{f}^{2}}{E_{f}} \cdot \frac{4 L_{f}^{3}}{h_{f}^{3}}\right)\left(P_{a}-P_{b}\right) & \alpha_{f}\left(\frac{T_{1,}}{h_{f}}\right)\left(1+v_{f}\right) T_{M} \\
\hline 0 & \alpha_{f} L_{T}\left[\left(1+v_{f}\right) T_{N}\right] \\
\hline
\end{array}
$$

Let

$$
R_{f}=\begin{array}{|l|l|}
\hline M_{f p} & M_{f t} \\
\hline N_{f p} & N_{f t} \\
\hline
\end{array}
$$

represent the unknown reactions at $f$, and

$$
\mathrm{n}_{\mathrm{f}}=\begin{array}{|c|c|}
\hline \theta_{f p} & \theta_{\mathrm{ft}} \\
\hline w_{f p} & w_{f t} \\
\hline
\end{array}
$$

represent the corresponding deflections. Then the matrix equation can be written as

$$
D_{f}=A_{f f} R_{f}+D_{f e}
$$

where

$$
A_{f f}=\begin{array}{|c|c|}
\hline \frac{1-v_{f}^{2}}{E_{f}} \cdot \frac{12 L_{f}}{h_{f}^{3}} & 0 \\
\hline 0 & \frac{1-v_{f}^{2}}{\ddots E_{f}} \cdot \frac{L_{f}}{\cdot l_{f}} \\
\hline
\end{array}
$$

represents the flexibility matrix giving the deflections $D_{f}$ produced by the reactions $R_{f}$ and

\footnotetext{
* Note that $Q_{f}=\left(P_{a}-P_{b}\right) L_{f}$. Also, the expansion by $T_{z}$ is the same at each weld of neighboring parallel plates and so produced no effect on weld reactions.
} 


$$
D_{f e}=\begin{array}{|c|c|}
\hline\left(\frac{1-v_{f}^{2}}{E_{f}} \cdot \frac{4 L_{f}^{3}}{h_{f}^{3}}\right)\left(P_{a}-P_{b}\right) & \alpha_{f}\left(\frac{L_{T}}{h_{f}}\right)\left(1+v_{f}\right) T_{M} \\
\hline 0 & \alpha_{f} L_{t}\left(1+v_{f}\right) T_{N} \\
\hline
\end{array}
$$

represents the deflections $D_{f}$ produced by the plate environment conditions of pressure and temperature. The reactions $R_{f}$ are given with respect to the weld reactions and the environment pressure in Eq (18). Here the equations are put in matrix form with the assumption that $N_{a}$ and $N_{b}$ are affected only by pressure, not temperature.

\begin{tabular}{|c|c|}
\hline $\mathbf{M}_{\mathrm{fp}}$ & $\mathbf{M}_{\mathrm{ft}}$ \\
\hline $\mathrm{N}_{\mathrm{fp}}$ & $\mathrm{N}_{\mathrm{ft}}$ \\
\hline 0 & -1 \\
\hline
\end{tabular}$\times$\begin{tabular}{|l|l|l|l|}
\hline-1 & $\mathrm{~L}_{\mathrm{sa}}$ \\
\hline $\mathbf{M}_{\mathrm{ap}}$ & $\mathbf{M}_{\mathrm{at}}$ \\
\hline $\mathbf{Q}_{\mathrm{ap}}$ & $\mathbf{Q}_{\mathrm{at}}$ \\
\hline
\end{tabular}

$$
+\begin{array}{|c|c|}
\hline+\left(L_{f a}+0.5 h_{a}-L_{f}\right) N_{a}-\left(L_{f b}+0.5 h_{b}-L_{f}\right) N_{b} & \\
-\left(L_{s a}-0.5 h\right)\left(P_{a} L_{p a}\right)-0.5\left(L_{f}-L_{f a}\right)^{2} P_{a} & 0 \\
+\left(L_{s b}-0.5 L_{p b}\right)\left(P_{b} L_{p b}\right)+0.5\left(L_{f}-L_{f b}\right)^{2} P_{b} & \\
\hline P_{a} L_{p a}+P_{b} L_{p b} & 0 \\
\hline
\end{array}
$$

Let

$$
\mathbf{R}_{\mathrm{a}}=\begin{array}{|l|l|}
\hline \mathbf{M}_{\mathrm{ap}} & \mathbf{M}_{\mathrm{at}} \\
\hline \mathbf{Q}_{\mathrm{ap}} & \mathbf{Q}_{\mathrm{at}} \\
\hline
\end{array} \quad \text { and } \quad \mathbf{R}_{\mathrm{b}}=\begin{array}{|l|l|}
\mathbf{M}_{\mathrm{bp}} & \mathbf{M}_{\mathrm{bt}} \\
\hline \mathbf{Q}_{\mathrm{bp}} & \mathbf{Q}_{\mathrm{bt}} \\
\hline
\end{array}
$$

represent the reactions at welds $a$ and $b$. Then,

$$
R_{f}=C_{f a} R_{a}+C_{f b} R_{b}+R_{f e}
$$

where

$$
C_{f a}=\begin{array}{|c|c|}
\hline-1 & L_{s a} \\
\hline 0 & -1 \\
\hline
\end{array}, \quad C_{f b}=\begin{array}{|c|c|}
\hline 1 & L_{s b} \\
\hline 0 & 1 \\
\hline
\end{array}
$$

and

$$
\mathbf{R}_{\mathrm{fe}}=\begin{array}{|c|c|}
\left(\mathrm{L}_{\mathrm{fa}}+0.5 \mathrm{~h}_{\mathrm{a}}-\mathrm{L}_{\mathrm{f}}\right) \mathrm{N}_{\mathrm{a}}-\left(\mathrm{L}_{\mathrm{fb}}+0.5 \mathrm{~h}_{\mathrm{b}}-\mathrm{L}_{\mathrm{f}}\right) \mathrm{N}_{\mathrm{b}} & \\
-\left(\mathrm{L}_{\mathrm{sa}}-0.5 \mathrm{~L}_{\mathrm{pa}}\right)\left(\mathrm{P}_{\mathrm{a}} \mathrm{L}_{\mathrm{pa}}\right)-0.5\left(\mathrm{~L}_{\mathrm{f}}-\mathrm{L}_{\mathrm{fa}}\right)^{2} \mathrm{P}_{\mathrm{a}} & 0 \\
+\left(\mathrm{L}_{\mathrm{sb}}-0.5 \mathrm{~L}_{\mathrm{pb}}\right)\left(\mathrm{P}_{\mathrm{b}} \mathrm{L}_{\mathrm{pb}}\right)+0.5\left(\mathrm{~L}_{\mathrm{f}}-\mathrm{L}_{\mathrm{fb}}\right)^{2} \mathrm{P}_{\mathrm{b}} & \\
\hline \mathrm{P}_{\mathrm{a}} \mathrm{L}_{\mathrm{pa}}+\mathrm{P}_{\mathrm{b}} \mathrm{L}_{\mathrm{bb}} & 0 \\
\hline
\end{array}
$$

Deflections at a

Putting Eq (20) in matrix form gives 


\begin{tabular}{|c|c|}
\hline$\theta_{\text {ap }}$ & $\theta_{\text {at }}$ \\
\hline$w_{\text {ap }}$ & $\mathbf{w}_{\text {at }}$ \\
\hline
\end{tabular}
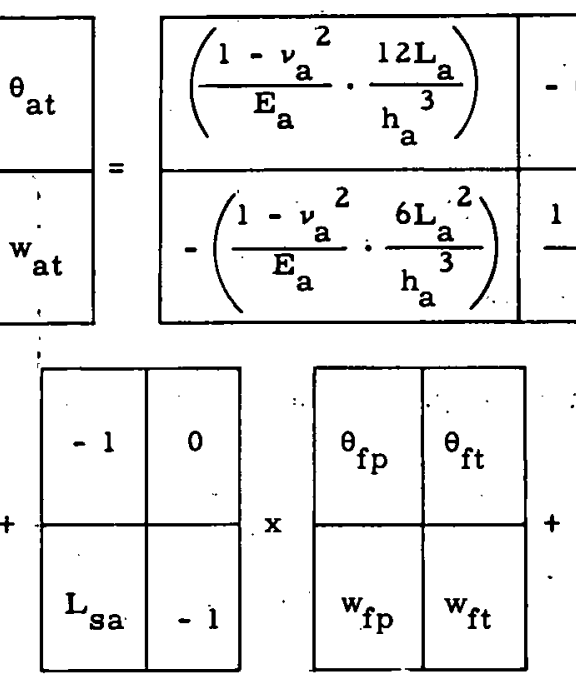

$$
\begin{aligned}
& -\left(\frac{1-v_{a}^{2}}{E_{a}} \cdot \frac{6 L_{a}^{2}}{h_{a}^{3}}\right) \\
& \frac{1-v_{a}^{2}}{E_{a}} \cdot \frac{4 L_{a}^{3}}{h_{a}^{3}}+\frac{1+v_{a}}{E_{a}} \cdot \frac{2.4 L_{a}}{h_{a}}
\end{aligned}
$$

\begin{tabular}{|l|l|}
\hline $\mathbf{M}_{\text {ap }}$ & $\mathbf{M}_{\text {at }}$ \\
\hline $\mathbf{Q}_{\text {ap }}$ & $\mathbf{Q}_{\text {at }}$ \\
\hline
\end{tabular}

Let

$$
D_{a}=\begin{array}{|l|l|}
\hline \dot{\theta}_{\text {ap }} & \theta_{\text {at }} \\
\hline w_{\text {ap }} & w_{\text {at }} \\
\hline
\end{array}
$$

represent the pressure and temperature components of the deflections at weld a.

Then,

$$
D_{a}=A_{a a} R_{a}+C_{f a}^{T} D_{f}+D_{a e}
$$

where

$$
A_{a a}=\begin{array}{|l|l|l|l}
\left(\frac{1-v_{a}^{2}}{E_{a}} \cdot \frac{12 L_{a}}{h_{a}^{3}}\right) & -\left(\frac{1-v_{a}^{2}}{E_{a}}\right)\left(\frac{6 L_{a}^{2}}{h_{a}^{3}}\right) \\
-\left(\frac{1-v_{a}^{2}}{E_{a}} \cdot \frac{6 L_{a}^{2}}{h_{a}^{3}}\right)\left(\frac{1-v_{a}^{2}}{E_{a}} \cdot \frac{4 L_{a}^{3}}{h_{a}^{3}}+\frac{1+v_{a}}{\mathrm{E}_{a}} \cdot \frac{12 L_{a}}{h_{a}}\right.
\end{array}
$$

represents the flexibility matrix giving the weld deflections $D_{a}$ in terms of the weld reactions $R_{a}$. $\mathrm{C}_{\mathrm{fa}}^{\mathrm{T}}$ is the transpose of $\mathrm{C}_{\mathrm{fa}}$ and

$$
D_{a a}=\begin{array}{|l|l|}
\hline\left(\frac{1-v_{a}^{2}}{E_{a}} \cdot \frac{2 L_{a}^{3}}{h_{a}^{3}}\right) P_{a} & 0 \\
\hline-\left(\frac{1-v_{a}^{2}}{E_{a}} \cdot \frac{1.5 L_{a}^{4}}{\left.h_{a}^{3}+\frac{1+v_{a}}{E_{a}} \cdot \frac{1.2 L_{a}^{2}}{h_{a}}\right) P_{a}}\right. & 0 \\
\hline
\end{array}
$$

represents the deflections at weld a in terms of the environment loading on the side plate near weld a.

\section{Deflections at $b$}

In the same way as for weld a, Eq (21) is put in the matrix form

$$
D_{b}=A_{b b} R_{a}+C_{f b}^{T} R_{f}+D_{b e}
$$


where

$$
\begin{aligned}
& D_{b}=\begin{array}{|c|c|}
\hline \theta_{b p} & \theta_{b t} \\
\hline w_{b p} & w_{b t} \\
\hline
\end{array} \\
& A_{b b}=\begin{array}{|l|l|}
\hline \frac{1-v_{b}^{2}}{E_{b}} \cdot \frac{12 L_{b}}{h_{b}^{3}} & \frac{1-v_{b}^{2}}{E_{b}} \cdot \frac{6 L_{b}^{2}}{h_{b}^{3}} \\
\hline \frac{1-v_{b}^{2}}{E_{b}} \cdot \frac{6 L_{b}^{2}}{h_{b}^{3}} & \frac{1-v_{b}^{2}}{E_{b}} \cdot \frac{4 L_{b}^{3}}{h_{b}^{3}}+\frac{1+v_{b}}{E_{b}} \cdot \frac{2.4 L_{b}}{h_{b}} \\
\hline
\end{array}
\end{aligned}
$$

and

$$
D_{b e}=\begin{array}{|l|l|}
\hline\left(\frac{1-v_{b}^{2}}{E_{b}} \cdot \frac{2 L_{b}^{3}}{h_{b}^{3}}\right) P_{b} & 0 \\
\hline\left(\frac{1-v_{b}^{2}}{E_{b}} \cdot \frac{1.5 L_{b}^{4}}{h_{b}^{3}}+\frac{1+v_{b}}{E_{b}} \cdot \frac{1.2 L_{b}^{2}}{h_{b}}\right) P_{b} & 0 \\
\hline
\end{array}
$$

Stresses at $a, b, c$, and $f$

Cross Section Stress-Let "in" represent the bottom surface of the side plate or the right surface of the parallel plate in Fig. 3, and let "out" represent the other surface. Then for any location on either plate, from Eq (7),

$$
\begin{aligned}
& \begin{array}{|l|l|}
\hline S_{x p(\text { in })} & S_{x t(\text { in })} \\
\hline S_{x p \text { (out) }} & S_{x t(o u t)} \\
\hline
\end{array}=\begin{array}{|c|c|c|}
\hline h^{2} & \frac{1}{h} \\
\hline-\frac{6}{h_{2}} & \frac{1}{h} \\
\hline
\end{array} \\
& +\begin{array}{|l|l|}
\hline 0 & \left(\frac{E \alpha}{1-v}\right)\left[\mathrm{T}_{\mathrm{N}}+0.5 \mathrm{~T}_{\mathrm{M}}-\mathrm{T}(\mathrm{in})\right] \\
\hline 0 & \left(\frac{\mathrm{E} \alpha}{1-v}\right)\left[\mathrm{T}_{\mathrm{N}}-0.5 \mathrm{~T}_{\mathrm{M}}-\mathrm{T} \text { (out) }\right] \\
\hline
\end{array}
\end{aligned}
$$

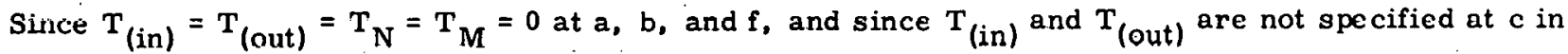
the S0131 code, the equation used in the code is simply

\begin{tabular}{|l|l|}
\hline$S_{x p(i n)}$ & $S_{x t(i n)}$ \\
\hline$S_{x p \text { (out) }}$ & $S_{x t(\text { out })}$ \\
\hline
\end{tabular}$=$\begin{tabular}{|c|c|}
\hline$h^{2}$ & $\frac{1}{h}$ \\
\hline$-\frac{6}{h^{2}}$ & $\frac{1}{h}$ \\
\hline
\end{tabular}

Thus, in examining the uutput of the code, the following correction should be made to $S_{x}$ at $c$ :

$$
\mathrm{S}_{\mathrm{x}}=\left(\mathrm{S}_{\mathrm{x}}\right)_{\text {code }}+\left(\frac{E \alpha}{1-v}\right) \cdot\left[\mathrm{T}_{\mathrm{N}}+\left(\frac{\mathrm{y}}{\mathrm{h}}\right) \mathrm{T}_{\mathrm{M}}-\mathrm{T}\right] \text {. }
$$

Axial Stress-The equation used for $S_{z}$ in the $S 0131$ code is

$$
\left(S_{z}\right)_{\text {code }}=v\left(S_{x}\right)_{\text {code }}+E \alpha\left(T_{z}-T_{N}\right) .
$$


Comparison of Eqs (3), (27), and (28) shows that the following correction should be made to obtain the true value of $S_{z}$ at $c$ :

$$
S_{z}=\left(S_{z}\right)_{\text {code }}+\left(\frac{E \alpha}{1-v}\right)\left[T_{N}+\left(\frac{v y}{h}\right) T_{M}-T\right] \text {. }
$$

Shear Stress-According to Eq (15), the shear stress at either surface is zero and the stress at the middle surface of a plate is maximum. This maximum shear stress in the S0131 code is correctly given by the following formula:

$$
\left(S_{S}\right)_{\text {code }}=1.5 \mathrm{Q} / \mathrm{h}
$$

for locations $a, b, c$, and $f$. Note that $s_{s}=0$ at $c$.

Parallel Plate Formulae

Weld Deflections

The weld deflections can be obtained in terms of weld reactions and environmental pressure and temperature loads by substituting the reaction $R_{f}$ from $E q(23)$ and the deflection $D_{f}$ from Eq (22) into the weld deflection equations. 'l'hus, in Eq (24)

$$
D_{a}=A_{a a} R_{a}+C_{f a}^{T}\left[A_{f f}\left(C_{f a} R_{a}+C_{f b} R_{b}+R_{f e}\right)+D_{f e}\right]+D_{a e}
$$

or

$$
D_{a}=\left(A_{a a}+C_{f a}^{T} A_{f f} C_{f a}\right) R_{a}+\left(C_{f a}^{T} A_{f f} C_{f b}\right) R_{b}+\left(C_{f a}^{T} A_{f f} R_{f e}+C_{f a}^{T} D_{f e}+D_{a e}\right) .
$$

Similarly, substitution in Eq (25) gives

$$
D_{b}=\left(C_{f b}^{T} A_{f f} C_{f a}\right) R_{a}+\left(A_{b b}+C_{f b}^{T} A_{f f} C_{f b}\right) R_{b}+\left(C_{f b}^{T} A_{f f} R_{f e}+C_{f b}^{T} D_{f e}+D_{b e}\right)
$$

\section{Weld Deflection Notation}

To keep track of individual plates and welds, the following notation is used.

Let

$\mathrm{n}=$ total number of parallel plates $(\mathrm{n} \leq 8$ in $\mathrm{S0} 131)$

$j=$ any plate, 1 to 8 , numbered from left to right, or the weld at the right end of the $j^{\text {th }}$ plate

$R_{j}=$ weld reactions at $b$ on plate $j$ or at a on plate $j+1 \quad i$ Note $R_{o}=R_{a}$ on plate $j=1 . \mid$

$D_{j}=$ working deflections of $R_{j}$ at weld $j \mid$ Note $D_{0}=D_{a}$ on plate $j=1$. |

Suppose that the plates between.welds $i$ and $j$ have been welded together so that the weld deflections $D_{i}$ and $D_{j}$ are determined by the weld reactions $R_{j}, R_{j}$ and the environment pressure and thermal loading between weld $i$ and $j$; that is, let

$$
\begin{aligned}
& \left(D_{1}\right)_{i j}=\left(A_{i i}\right)_{i j} R_{1}+\left(A_{i j}\right)_{i j} R_{j}+\left(D_{i e}\right)_{i j} \\
& \left(D_{j}\right)_{i j}=\left(A_{j i}\right)_{i j} R_{i}+\left(A_{j j}\right)_{i j} R_{j}+\left(D_{j e}\right)_{i j},
\end{aligned}
$$

where

$\left(D_{i}\right)_{i j}=D_{i}$ on the $p l=$ ses $i+1, i+2, \ldots, j$ welded together between welds $i$ and $j$,

$\left(A_{i j}\right)_{i j}=$ flexibility matrix giving $\left(D_{i}\right)_{i j}$ in terms of $R_{j}$,

and

$\left(D_{i e}\right)_{i j}=D_{i}$ produced by environment between $i$ and $j$. 
In particular, if $i=j-1$, then for plate $j$, a comparison of Eqs (31), (32), and (33) shows that

$$
\begin{gathered}
\left(A_{j-1, j-1, j-1, j}=A_{a a}+C_{f a}^{T} A_{f f} C_{f a}\right. \\
\left(A_{j-1, j}\right)_{j-1, j}=C_{f a}^{T} A_{f f} C_{f b} \\
\left(D_{j-1, e}\right)_{j-1,1}=C_{f a}^{T} A_{f f} R_{f e}+C_{f a}^{T} D_{f e}+D_{a e} \\
\left(A_{j, j-1}\right)_{j-1, j}=C_{f b}^{T} A_{f f} C_{f a} \\
\left(A_{j j}\right)_{j-1, j}=A_{b b}+C_{f b}^{T} A_{f f} C_{f b} \\
\left(D_{j e}\right)_{j-1, j}=C_{f b}^{T} A_{f f} R_{f e}+C_{f b}^{T} D_{f e}+D_{b e} .
\end{gathered}
$$

Because of the reciprocal theorem*, the following relationships exist for the flexibility matrices in Eq (33):

1) $\left(A_{i j}\right)_{i j}$ and $\left(A_{j j}\right)_{i j}$ are symmetrical; that is, $\left(A_{i i}\right)_{i j}=\left(A_{i j}^{T}\right)_{i j}$ and $\left(A_{j j}\right)_{i j}=\left(A_{j j}^{T}\right){ }_{i j}$.

2) $\left(A_{i j}\right)_{i j}$ and $\left(A_{j i}\right)_{i j}$ are transposes of each other; that is $\left(A_{i j}\right)_{i j}=\left(A_{j i}^{T}\right)_{i j}$ and $\left(A_{j i}\right)_{i j}=\left(A_{i j}^{T}\right)_{i j}$.

\section{Combination of Parallel Plates}

The basic equations are now avallable for combining groups of parallel plates. Suppose the equations for the group of plates between welds $i$ and $j$ and for the group of plates between welds $j$ and $k$ are known. At the joint $j$, the working deflections of the weld reactions $R_{j}$ on the group of plates between $i$ and $j$ are $\left(D_{j}\right)_{i j}$ and the working deflections of $R_{j}$ on the group of plates between $j$ and $k$ are $\left(D_{j}\right)_{j k}$. When the groups $i j$ and $j k$ are joined to form a single group $i k$, the reactions $R_{j}$ become internal and can do no work; that is, the net working deflection must be zero. Thus,

$$
0=\left(D_{j}\right)_{i j}+\left(D_{j}\right)_{j k}
$$

Substituting deflections from Eq (33) into the preceding equation gives

$$
0=\left[\left(A_{j i}\right)_{i j} R_{i}+\left(A_{j j}\right)_{i j} R_{j}+\left(D_{j e}\right)_{i j}\right]+\left[\left(A_{j j}\right)_{j k} R_{j}+\left(A_{j k}\right)_{j k} \times R_{k}+\left(D_{j e}\right)_{j k}\right]
$$

or

$$
0=\left(A_{j i}\right)_{i j} R_{i}+\left[\left(A_{j j}\right)_{i j}+\left(A_{j j}\right)_{j k}\right] R_{j}+\left(A_{j k}\right)_{j k} R_{k}+\left[\left(D_{j e}\right)_{i j}+\left(D_{j e}\right)_{j k}\right] .
$$
This can be solved for $R_{j}$ by multiplying each term by the inverse matrix of $\left[\left(A_{j j}\right)_{i j}+\left(A_{j j}\right)_{i k}\right]$. The
result is

$$
R_{j}=\left(C_{j i}\right)_{i k} R_{i}+\left(C_{j k}\right)_{i k} R_{k}+\left(R_{j e}\right)_{i k}
$$

where

$$
\left(R_{j e}\right)_{i k}=-\left[\left(A_{j j}\right)_{i j}+\left(A_{j j}\right)_{j k}\right] I \times\left[\left(D_{j e}\right)_{i j}+\left(D_{j e}\right)_{j k}\right] \text {. }
$$$$
\begin{aligned}
& \left(C_{j i}\right)_{i k}=-\left[\left(A_{j j}\right)_{i j}+\left(A_{j j}\right)_{j k}\right] \times\left(A_{j i}\right)_{i j} \\
& \left(C_{j k}\right)_{1 k}=-\left[\left(A_{j j}\right)_{i j}+\left(A_{j j}\right)_{j k}\right]^{I} \times\left(A_{j k}\right)_{j k^{\prime}}
\end{aligned}
$$

* The working deflection of one load produced by a unit value of a second load equals the working deflection of the second load produced by a unit value of the first load. 
Substitution of the reactions $R_{j}$ from $E_{q}(35)$ into equations for $\left(D_{i}\right)_{i j}$ and $\left(D_{k}\right)_{k j}$ of the form of Eq (33) gives

$$
\left\langle D_{i}\right)_{i j}=\left(A_{i i}\right)_{i j} R_{i}+\left(A_{i j}\right)_{i j}\left[\left(C_{j i}\right)_{i k} R_{i}+\left(C_{j k}\right)_{i k} R_{k}+\left(R_{j e}\right)_{i k}\right]+\left(D_{i e}\right)_{i j}
$$

or

$$
\left(D_{i j}\right)_{i j}=\left[\left(A_{i i}\right)_{i j}+\left(A_{i j}\right)_{i j}\left(C_{j i}\right)_{i k}\right] R_{i}+\left[\left(A_{i j}\right)_{i j}\left(C_{j k}\right)_{i k}\right] R_{k}+\left[\left(A_{i j}\right)_{i j}\left(R_{j e}\right)_{i k}+\left(D_{i e}\right)_{i j}\right] \text {, }
$$

and similarly,

$$
\left(D_{k}\right)_{j k}=\left[\left(A_{k j}\right)_{j k}\left(C_{j i}\right)_{i k}\right] R_{i}+\left[\left(A_{k j}\right)_{j k}\left(C_{j k}\right)_{i k}+\left(A_{k k}\right)_{j k}\right] R_{k}+\left[\left(A_{k j}\right)_{j k}\left(R_{j e}\right)_{j k}+\left(D_{k e}\right)_{j k}\right] \text {. }
$$

These equations are seen to be in the standard form

$$
\begin{gathered}
\left(D_{i}\right)_{i k}=\left(A_{i i}\right)_{i k} R_{i}+\left(A_{i k}\right)_{i k} R_{k}+\left(D_{i e}\right)_{i k} . \\
\left(D_{k}\right)_{i k}=\left(A_{k i}\right)_{i k} R_{i}+\left(A_{k k}\right)_{i k} R_{k}+\left(D_{k e}\right)_{i k},
\end{gathered}
$$

where

$$
\begin{aligned}
& \left(A_{i j}\right)_{i k}=\left(A_{i j}\right)_{i j}+\left(A_{i j}\right)_{i j}\left(C_{j i}\right)_{i k} \\
& \left(A_{i k}\right)_{i k}=\left(A_{i j}\right)_{i j}\left(C_{j k}\right)_{i k} . \\
& \left(D_{i e}\right)_{i k}=\left(A_{i j}\right)_{i j}\left(R_{j e}\right)_{i k}+\left(D_{i e}\right)_{i j^{\prime}} \\
& \left(A_{k j}\right)_{i k}=\left(A_{k j}\right)_{j k}\left(C_{j i}\right)_{i k}, \\
& \left(A_{k k}\right)_{i k}=\left(A_{k j}\right)_{j k}\left(C_{j k}\right)_{i k}+\left(A_{k k^{\prime}}\right)^{\prime}
\end{aligned}
$$

and

$$
\left(D_{k e}\right)_{i k}=\left(A_{k j}\right)_{j k}\left(R_{j e}\right)_{i k}+\left(D_{k e}\right)_{j k} \cdot
$$

By repeated use of Eqs (35) and (36), all the parallel plates of the subassembly are joined together and the weld reactions are determined. This procedure is followed in code S0131, as shown in the flow diagram in Fig. 7.

\section{INPUT AND OUTPUT DATA}

\section{Input Carda}

The regular Wolontis format is used on the input cards.

Columns
$7-9$
10
$11-21$
$22-32$

Contents

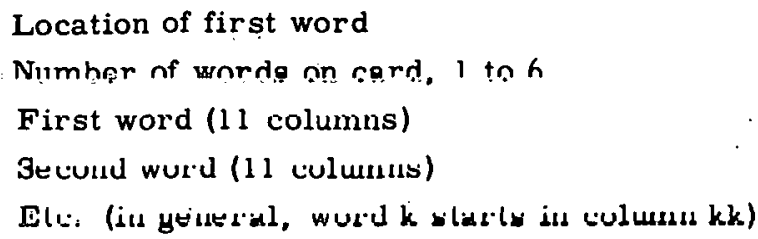

The sign of a word is given first and 10 digits follow. If the word is fixed (fix), the significant digits are at the right side, for example, -23 (fix) is - 0000000023. If the word is not fixed, it is in Wolontis floating form; that is, if a number $N$ is put on a card in the form $\pm a b c d e f g h$ i the actual number is $\dot{N}= \pm\left(a . b \mathrm{cdef} \mathrm{g} \mathrm{h}\right.$ ) $\times 10^{1 \mathrm{j}-50}$. Thus, -23 is -2300000051 and +.0173 is +1730000048 . Table I gives the format of input cards.

There are three cards of preliminary data and 2 n sets of plate data, each set consisting of 4 cards or 1 card. Four cards are used for the first plate and each plate different from the preceding 

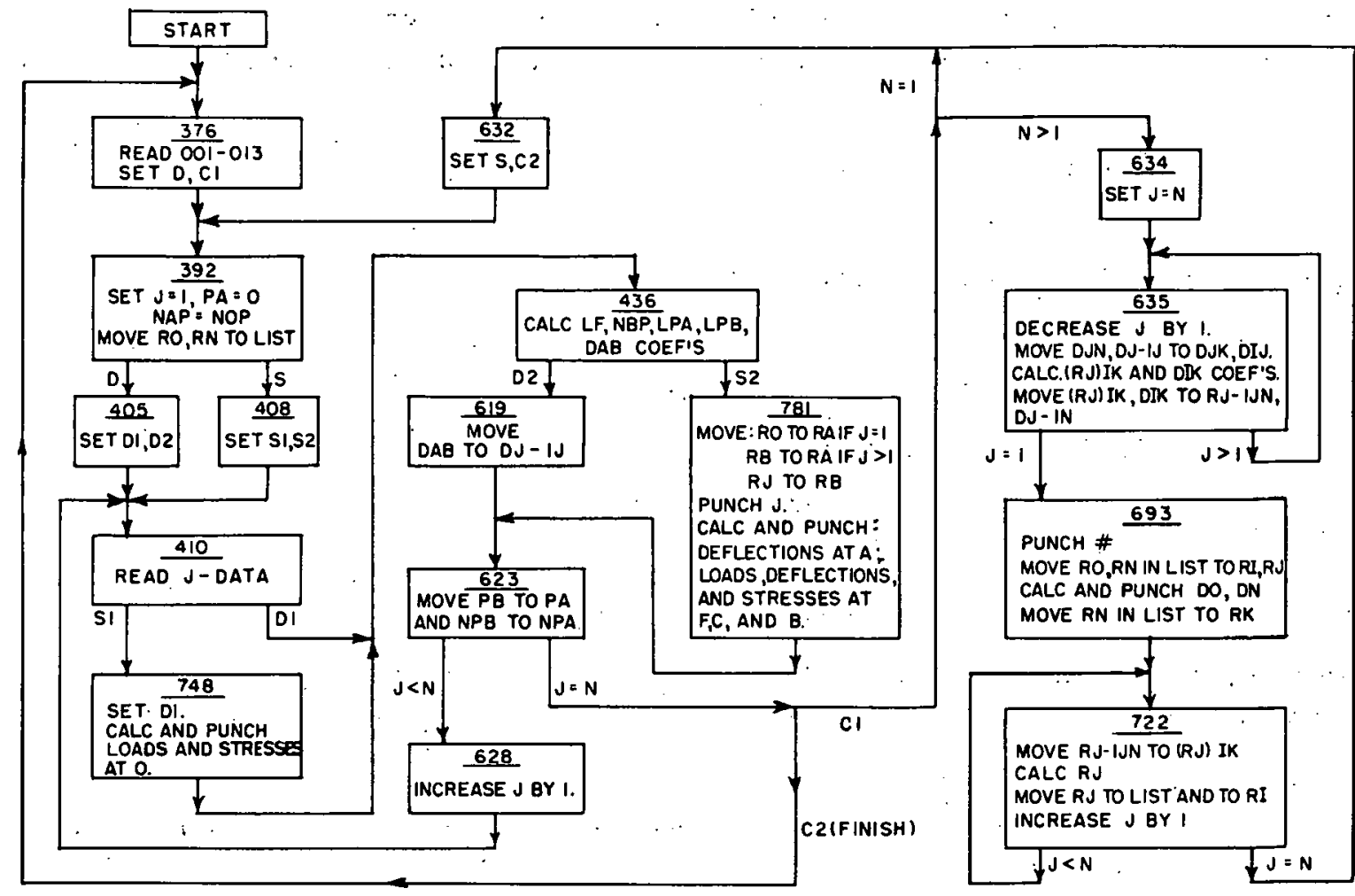

Fig. 7 Flow Diagram for 50131

TABLE I

INPUT DATA FORMAT

\begin{tabular}{|c|c|c|c|c|c|c|c|c|}
\hline $7-9$ & 10 & $11-21$ & $22-32$ & $33-43$ & $44-54$ & $55-65$ & $66-76$ & Columns \\
\hline 001 & 5 & $\#$ & $\alpha$ & $\mathrm{T}_{\mathbf{z}}$ & $n(f i x)$ & $\mathrm{N}_{\mathrm{op}}$ & & Three cards of \\
\hline 006 & 4 & $M_{o p}$ & $Q_{o p}$ & $M_{\text {ot }}$ & $Q_{\text {ot }}$ & & & preliminary \\
\hline 010 & 4 & $\mathbf{M}_{\mathrm{np}}$ & $Q_{n p}$ & $\mathbf{M}_{\underline{n} \mathbf{n}}$ & $Q_{n t}$ & & & data \\
\hline 014 & 6 & $P_{b}$ & $\mathbf{T}_{\mathbf{M}}$ & $\mathrm{T}_{\mathrm{N}}$ & $\mathbf{L}_{T}$ & +0 & $J(f i x)$ & 4-card set of \\
\hline 019 & 6 & $E_{s}$ & $v_{s}$ & $E_{f}$ & $\nu_{f}$ & $h_{f}$ & $J(f i x)$ & data for plate $j$ \\
\hline 024 & 5 & $h_{a}$ & $h_{b}$ & $\mathrm{~L}_{\mathbf{s a}}$ & $\mathrm{L}_{\mathrm{sb}}$ & $J(f i x)$ & & $(j=1$ to $N)$ \\
\hline 028 & 5 & $\mathrm{~L}_{\mathrm{a}}$ & $\mathrm{L}_{\mathrm{b}}$ & $\mathrm{L}_{\mathrm{fa}}$ & $\mathrm{L}_{\mathrm{fb}}$ & $J(f i x)$ & & \\
\hline U14 & 6 & $\mathbf{F}_{b}$ & $\mathbf{T}_{\mathrm{M}}$ & $T_{N}$ & $\mathrm{~L}_{\mathrm{T}}$ & $J(f \mid x)$ & $\mathbf{E}_{\mathbf{S}}$ & $\begin{array}{l}\text { l-card set of } \\
\text { data for plate }\end{array}$ \\
\hline
\end{tabular}


plate in materials or geometry; only one modified card need be used for a plate which is the same in materials and geometry as the preceding plate. The input data cards are arranged in the following order:

(x) 3 cards of preliminary data

(y) $\left\{\begin{array}{l}4 \text { cards of data for first plate } \\ 4 \text { cards (or } 1 \text { modified card) of data for second plate } \\ 4 \text { cards (or } 1 \text { modified card) of data for last plate }\end{array}\right.$

(z) $\left\{\begin{array}{l}4 \text { cards of data for first plate. } \\ 4 \text { cards (or } 1 \text { modified card) of data for second plate } \\ 4 \text { cards (or } 1 \text { modified card) of data for last plate }\end{array}\right.$

Note that the plate data cards are repeated; that is, group (z) is the same as group (y). The running time on the IBM-650 is about two minutes per plate per problem. The following notations are used:

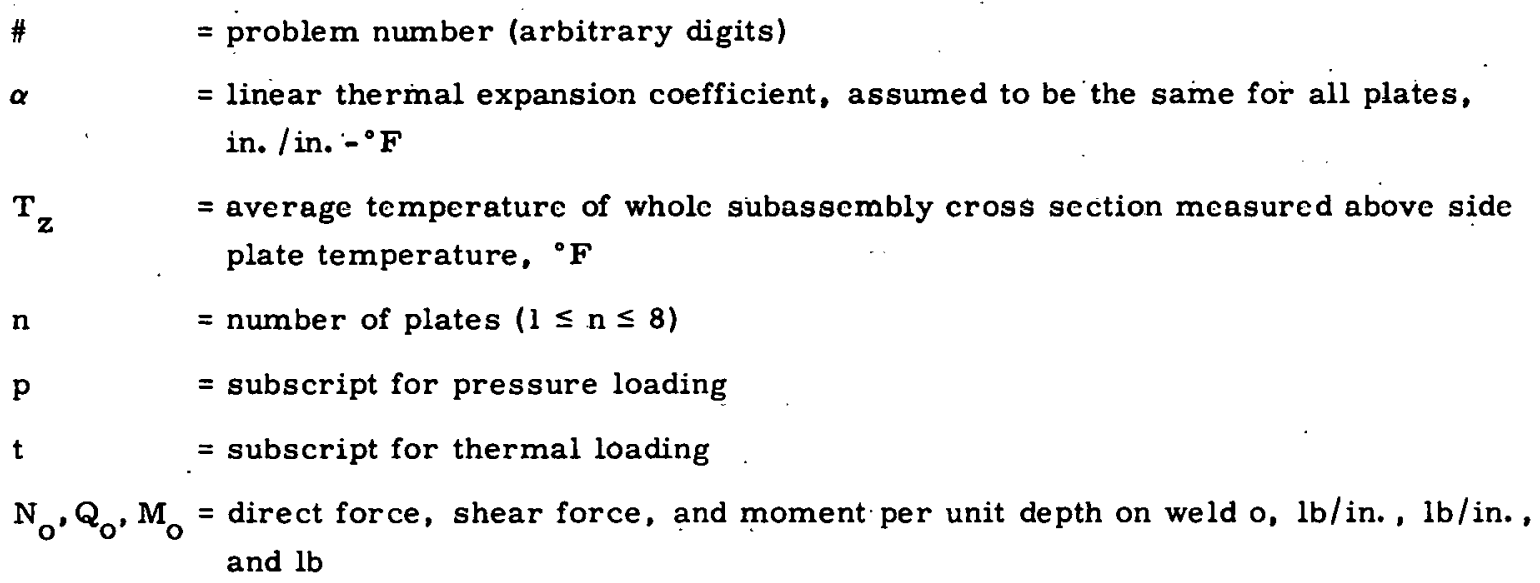
and $\mathrm{lb}$

Noto aymmotry;

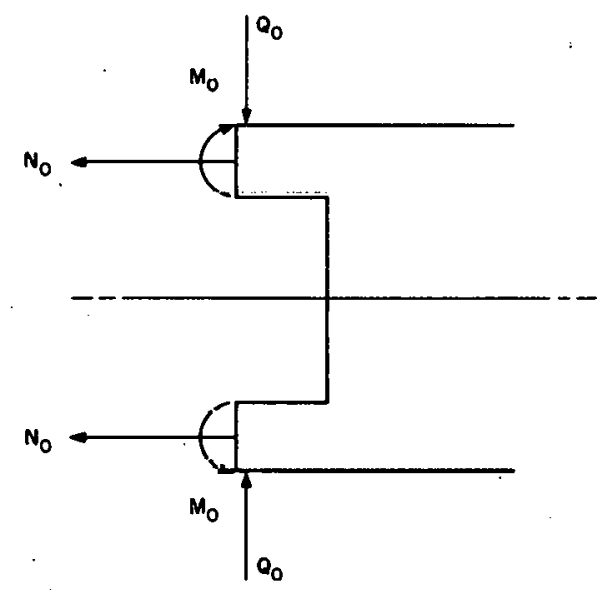

$Q_{n}, N_{n} \quad=$ shear force and moment per, unit depth on weld $n, l b /$ in. and $l b / i n$.

$\mathrm{p}_{\mathrm{b}} \quad=$ channel pressure on right side of parallel plate $\mathbf{j}$ measured above external pressure, psi 


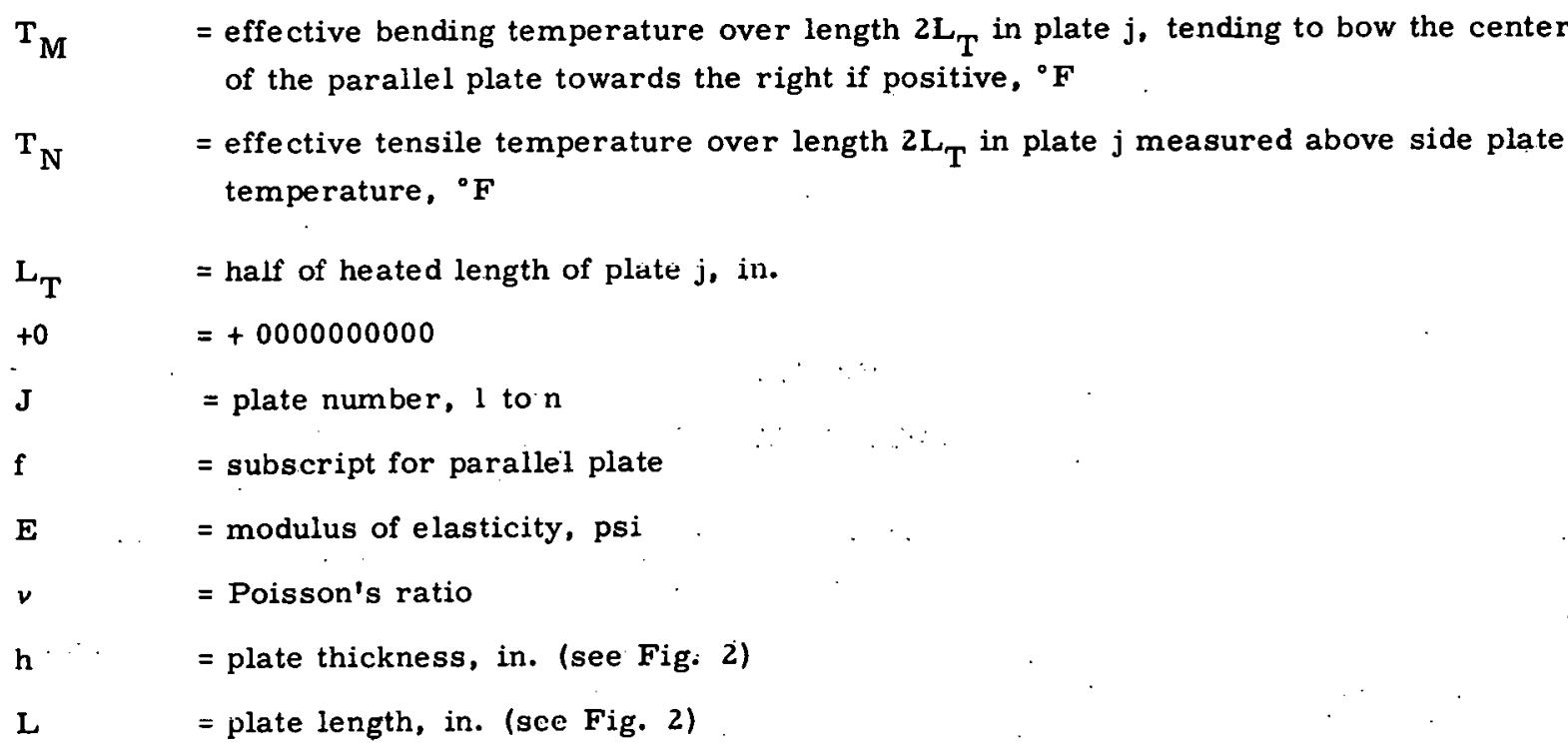

\section{Output Cards}

The following additional notations are used for the output cards shown in Table II:

w $\quad$ deflection in. (see Fig. 6)

$\mathrm{S}_{\mathrm{x}} \quad=$ cross section stress, psi [see Eqs (26) and (27)]

$\mathrm{S}_{\mathrm{z}} \quad$ axial stress, psi [see Eqs (28) and (29)]

$\mathrm{S}_{\mathrm{S}} \quad=$ shear stress in middle surface, psi [see Eq (30)]

- $\quad$ subscript for left weld on plate 1

$\mathrm{n} \quad=$ subscript for right weld on plate $\mathrm{n}$

in $\quad=$ notation for bottom surface of: side plate or right surface of parallel plate (see Fig. 3)

out $\quad=$ notation for top surface of side platc or right surface of parallel plate.

$a, b, c, f=$ subscripts for locations shown in Fig. 3

$\mathbf{M}$

= bending moment per unit depth, lb (see Fig. 3); note $M_{c}=M_{f}+Q_{f} L_{f}+\left(L_{f}^{2} / 2\right)$ $\left(P_{b}-P_{d}\right)$

Q = shear force per unit depth, lb/in. (see Fig. 3)

$\mathrm{N} \quad=$ tensile force per unit depth, lb/in. (see Fig. 3); note $\mathrm{N}_{c}=\mathrm{N}_{\mathrm{f}}$

Figure 8 shows a sample problem solved with code S0131. The input cards and data cards are listed in Table III, along with the output cards for the first three plates. Since the stresses and deflections decrease in magnitude away from the end plate, only the results in the first two or three plates are important.

\section{REFERENCE}

1. S. Timoshenko, Theory of Plates and Shells, (McGraw-Hill Book Co., New York, 1940 ). 
TABLE II

OUTPUT DATA FORMAT

\begin{tabular}{|c|c|c|c|c|c|c|c|c|}
\hline $7-9$ & 10 & $21-31$ & $22-32$ & $33-43$ & $44-54$ & $.55-65$ & $66-76$ & Columns \\
\hline 001 & 1 & $\#$ & & & & & & \\
\hline 112 & 4 & $\theta_{\text {op }}$ & $w_{\text {op }}$ & $\theta_{\text {ot }}$ & $w_{n t}$ & . & & $\begin{array}{l}\text { Preliminary } \\
\text { output data }\end{array}$ \\
\hline 116 & 4 & $\theta_{n p}$ & $w_{n p}$ & $\theta_{\text {nt }}$ & $w_{n t}$ & ' & & \\
\hline 187 & 6 & $\mathbf{M}_{\mathrm{op}}$ & $Q_{\text {op }}$ & $\mathbf{M}_{\text {ot }}$ & $Q_{\text {ot }}$ & $\mathbf{N}_{\text {op }}$ & $\mathrm{N}_{\text {ot }}$ & . \\
\hline 193 & 6 & $S_{x o p(i n)}$ & $S_{\text {xop (out) }}$ & $\mathbf{S}_{x o t}(i n)$ & $S_{\text {xot (out) }}$ & $\mathbf{S}_{\text {sop }}$ & $s_{\text {sot }}$ & Location 0 \\
\hline 199 & 4 & $S_{z o p(i n)}$ & $S_{\text {zop (out) }}$ & $\mathbf{S}_{\text {zot (in) }}$ & $S_{\text {zot }(o u t)}$ & & & \\
\hline 038 & 1 & $J(f i x)$ & & & $:$ & & & Output data \\
\hline 205 & 6 & $\theta_{\text {ap }}$ & $\mathbf{w}_{\text {ap }}$ & $\theta_{\text {at }}$ & $\mathbf{w}_{\text {at }}$ & $\theta_{\text {fp }}$ & $w_{f p}$ & for plate $\mathrm{J}$ \\
\hline 211 & 6 & ${ }^{0} \mathrm{ft}$ & $\mathbf{w}_{\mathrm{ft}}$ & $\theta_{b p}$ & $w_{b p}$ & $\theta_{b t}$ & $\mathrm{w}_{\mathrm{bt}}$ & $(\mathrm{J}=1$ to $\mathrm{n})$ \\
\hline 217 & 2 & $w_{c p}$ & $w_{c t}$ & . & . & & & \\
\hline 187 & 6 & $\mathrm{M}_{\mathrm{fp}}$ & $Q_{f p}$ & $\mathbf{M}_{\mathrm{ft}}$ & $Q_{f t}$ & $N_{f p}$ & $\mathrm{~N}_{\mathrm{ft}}$ & \\
\hline 193 & 6 & $S_{x f p(i n)}$ & $S_{\text {xfp (out) }}$ & $S_{x f t(i n)}$ & $\underline{S}_{x f l(u u l)}$ & $S_{\text {sfp }}$ & $S_{s f i}$ & Inration f \\
\hline 199 & 4 & $s_{z f p(i n)}$ & $S_{\text {zfp(out) }}$ & $s_{z f p(i n)}$ & $s_{\text {zfp(out) }}$ & & . & \\
\hline 107 & 6 & $\mathrm{M}_{c p}$ & $Q_{c p}$ & $\mathrm{IM}_{\mathrm{CL}}$ & $\mathbf{Q}_{\mathbf{c t}}$. & $\mathrm{N}_{\mathrm{cp}}$ & Not. & \\
\hline 193 & 6 & $S_{x \in p(I n)}$ & $S_{\text {sup }}($ uul $)$ & $S_{\text {Aul }(I u)}$ & $S_{x c r(o u t)}$ & $S_{\mathrm{sic} \overline{\mathrm{p}}}$ & $\mathrm{S}_{\text {sct }}$ & Loontion ! \\
\hline 199 & 4 & $S_{z c p(i n)}$ & $S_{z c p \text { (out) }}$ & $S_{z \operatorname{ct}(i n)}$ & $S_{z \operatorname{ct}(\text { out })}$ & & & \\
\hline 187 & 6 & $\mathrm{M}_{\mathrm{bp}}$ & $\mathrm{Q}_{\mathrm{bp}}$ & $\mathbf{M}_{\mathrm{bt}}$ & $\mathbf{Q}_{\mathrm{bt}}$ & $\mathbf{N}_{h p}$ & $\mathrm{~N}_{b t}$ & \\
\hline 193 & 6 & $S_{x b p(i n)}$ & $S_{x b p \text { (out) }}$ & $S_{x b t(i n)}$ & $S_{x b t(\text { out) }}$ & $s_{\text {sbp }}$ & $S_{\text {sbt }}$ & Location $b$ \\
\hline 199 & 4 & $S_{z b p(i n)}$ & $S_{\text {zbp (out) }}$ & $\mathbf{S}_{\mathrm{zbt}(\mathrm{in})}$ & $S_{z \text { bt (out) }}$ & & & \\
\hline
\end{tabular}




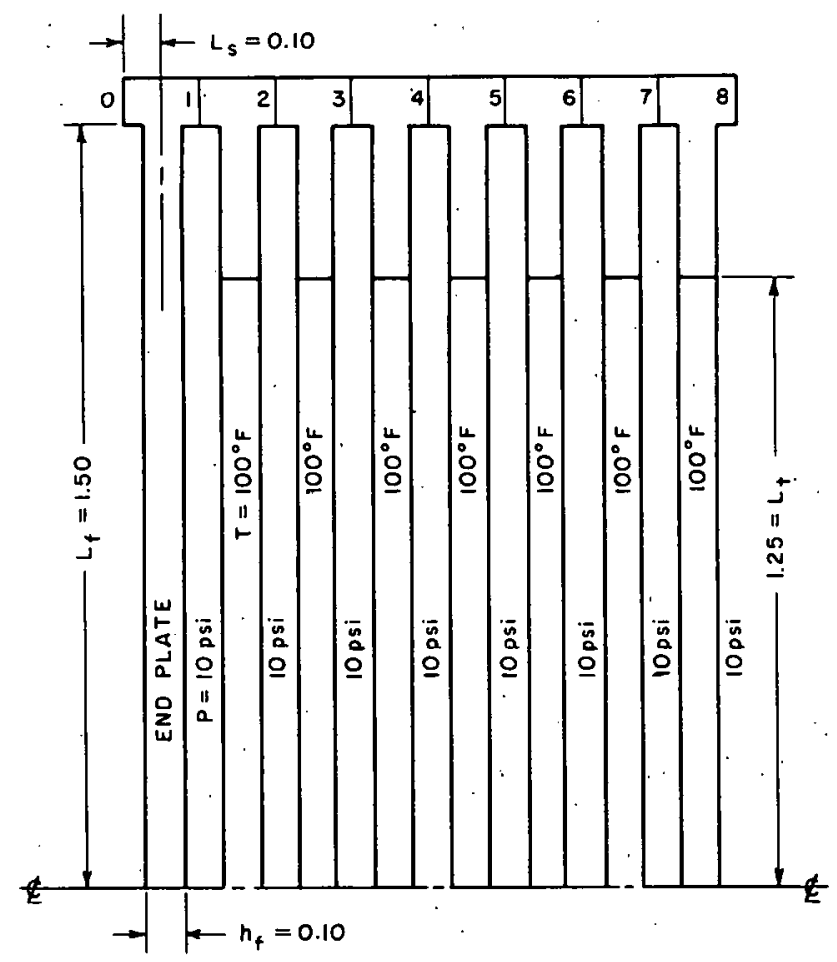

Fig. 8 Sample Problem Solved with the SOI3I
Code 


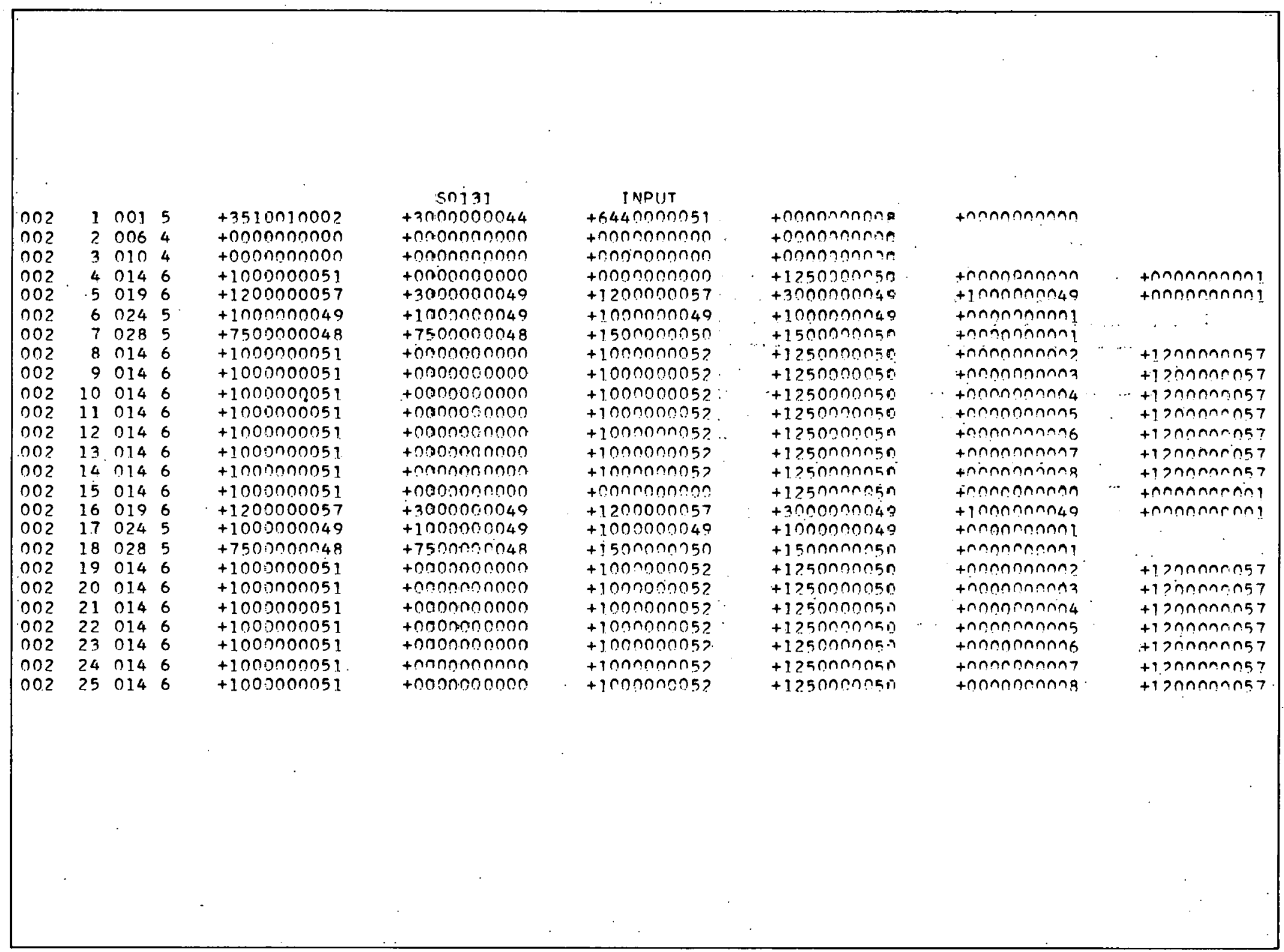


TABLE III (Cont)

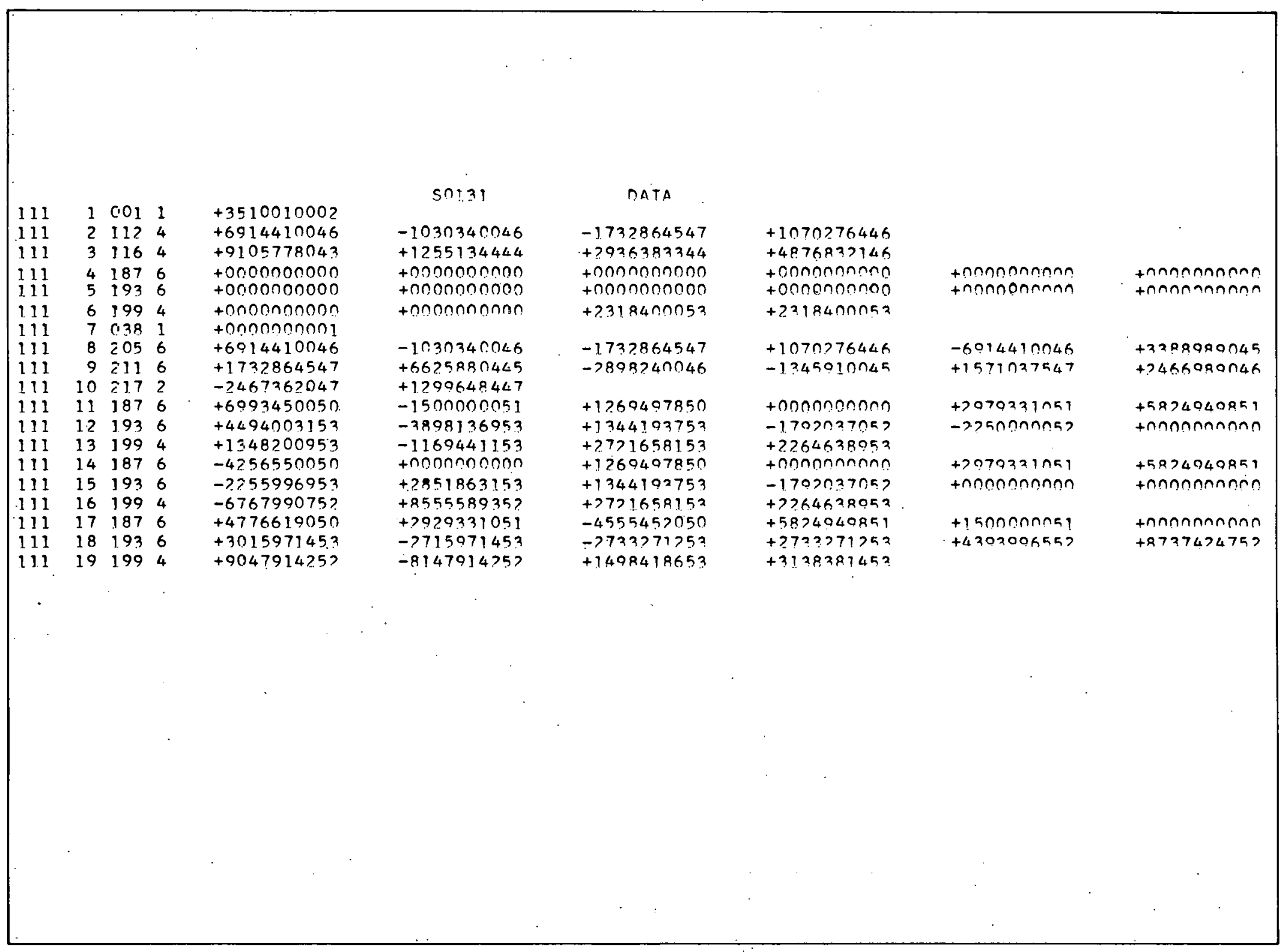


TABLE III (Cont)

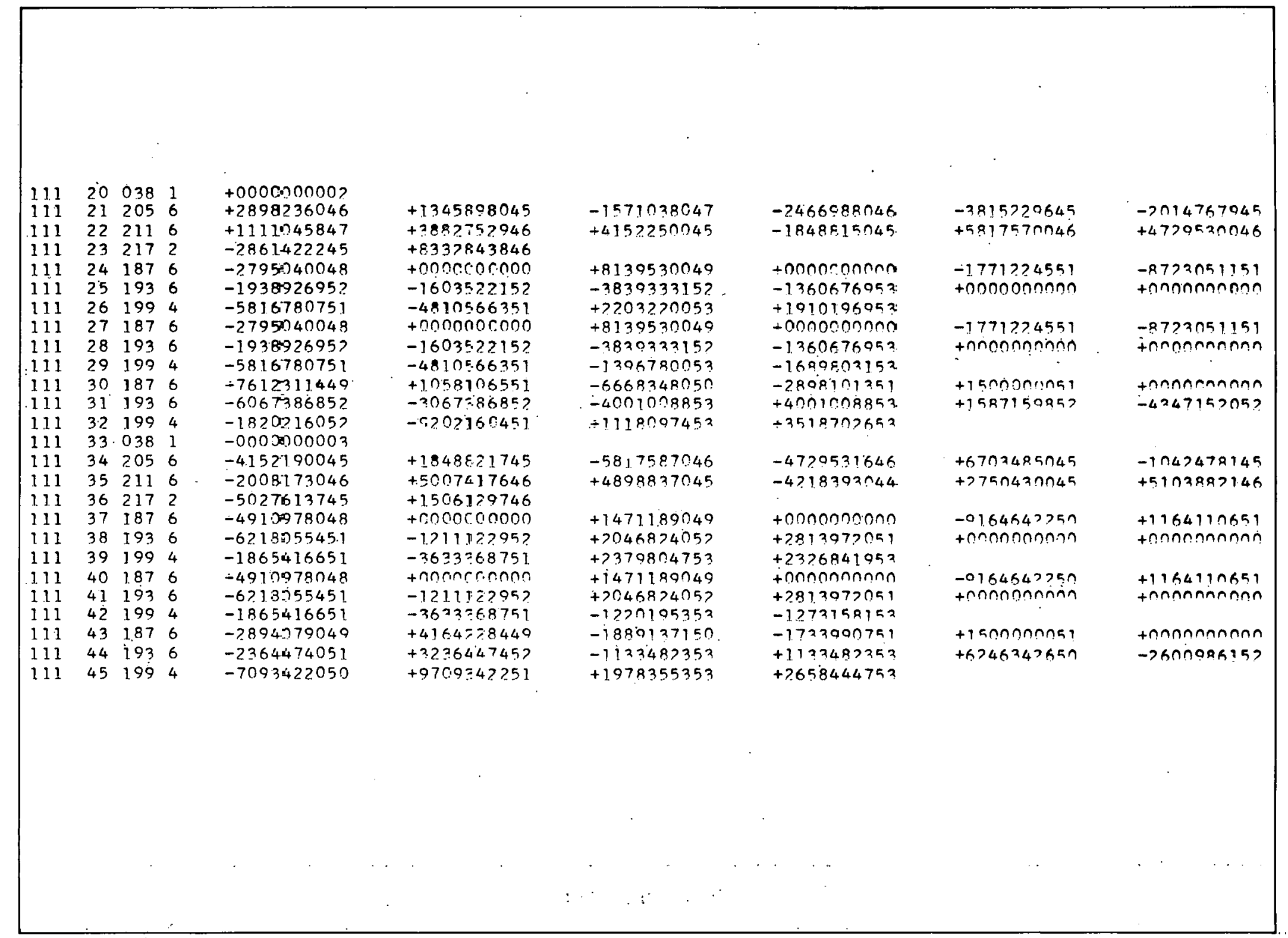

